\title{
História natural da perda auditiva ocupacional provocada por ruído
}

\author{
S. I. C. de Almeida, P. L. M. Albernaz, P. A. Zaia, O. G. Xavier, E. H. I. Karazawa
}

Divisão de Segurança e Saúde do Trabalhador DRT/SP; Departamento de Otorrinolaringol ogia e Distúrbios da Comunicação Humana da Universidade Federal de São Paulo - Escola Paulista de Medicina, Serviço Médico de Saúde do Trabal hador do Sesi, São Paulo, SP.

\begin{abstract}
RESUMO - Овj etıvo. Analisar as características clínicas e audiométricas da disacusia sensórioneural ocupacional por ruído de acordo com a faixa etária e o tempo de exposição em anos.

MÉTodo. Foram estudados retrospectivamente 222 pacientes portadores de disacusia sensórioneural ocupacional decorrente da exposição ao ruído no ambiente de trabalho, correlacionando-se as queixas clínicas auditivas, alterações de limiar audiométrico nas freqüências de $250 \mathrm{~Hz}$ a $8000 \mathrm{~Hz}$, índices de discriminação vocal com a faixa etária e o tempo de exposição. Como grupo controle, utilizouse os limiares audiométricos de uma população de mesma média etária, sem antecedentes mórbidos de doença auditiva, conforme preconiza a norma ISO 1999 (1990). O grupo foi dividido em subgrupos, tendo-se analisado três décadas de exposição.

Resultados. Verificamos que a queixa clínica de hi poacusia aumenta de acordo com a faixa etária e o tempo de exposição, enquanto que a freqüência da queixa tinnitus mantém-se constante. Os Limiares
\end{abstract}

\section{INTRODUÇÃO}

O som é um agente físico resultante da vibração de moléculas do ar e que se transmite como uma onda longitudinal. É, portanto, uma forma de energia mecânica (WHO, 1980) ${ }^{1}$.

O receptor periférico sensível a esta forma de energia, captando-a e transformando-a em impulso elétrico nervoso é o orel ha.

O aparel ho auditivo humano consegue detectar variações de pressão do ar numa faixa de 0,00002 a $200 \mathrm{Newton} / \mathrm{m}^{2}$ no limiar de audibilidade de freqüências que é de 16 a $20.000 \mathrm{~Hz}$. Portanto, nem toda onda sonora evoca a sensação auditiva.

Ruído é uma palavra derivada do latim rugitu que significa estrondo. Acusticamente é constituído por várias ondas sonoras com relação de amplitude e fase distribuídas anarquicamente, provocando uma sensação desagradável, diferente da música.

O ruído pode ser contínuo, ou seja, não há variação do nível de pressão sonora nem do espectro sonoro; de impacto ou impulsivo que são ruídos de alta energia audiométricos na segunda década de exposição apresentam variações que dependem da faixa etária analisada. As várias curvas audiométricas realizadas são paralelas entre si, mas não-horizontais, sendo que os piores limiares foram encontrados nas freqüências agudas de $3000 \mathrm{~Hz}$ a $8000 \mathrm{~Hz}$, como conseqüência clínica e fisiopatológica do acometimento mais acentuado das áreas basais da cóclea. A discriminação vocal também mostrou-se pior de acordo com 0 aumento das faixa etária e do tempo de exposição.

Conclusão. Indivíduos portadores de disacusia sensórioneural por ruído ocupacional apresentam alterações audiométricas, características que variam de acordo com a faixa etária e o tempo de exposição. Estas características definidas e resumidas nas curvas audiométricas obtidas podem constituir padrão de comparação, avaliação e controle de outras populações também expostas.

UNITERMOS: Perda auditiva por ruído. Hipoacusia. Epidemiologia.

e que duram menos de 1 segundo (ISO 1973a) ${ }^{2}$.

A mensuração do ruído pode ser realizada através de dosímetros. Estes aparelhos estimam o nível equival ente de energia (L eq) que atinge o indivíduo durante o período de medição que poderá variar de minutos até a jornada de trabalho integral.

Apesar das variações, através de estudos populacionais preliminares, sabe-se que o ruído industrial apresenta níveis médios de exposição de 90 $\mathrm{dB}$ Leq $8 \mathrm{~h}$ com desvio de $\pm 5 \mathrm{~dB}$ (Hetu, Quoc, Duguay, 1990) ${ }^{3}$, constituindo este um parâmetro para realizar-se projeções.

E mbora a disacusia sensórioneural ocupacional por ruído seja uma doença de alta prevalência nos países industrializados, incluindo-se o Brasil, os estudos sobre a sua história natural são escassos, principalmente em nosso meio.

Tanto nos Estados Unidos quanto na Europa, estes trabalhos receberam grande incentivo devido ao alto custo social e econômico que passaram a acarretar às indústrias na década de 40, devido aos constantes processos judiciais e indenizatórios. 
A partir dessa época, fatores de prevenção do problema, assim como os fatores de risco, passaram a ser alvos de estudos clíni cos e experimentais em todo o mundo. Pesquisam-se períodos de exposições diários e níveis sonoros seguros para o não desencadeamento da lesão auditiva.

Embora a doença atinja proporções endêmicas em nosso meio industrial, os estudos são escassos fazendo com que importemos o conhecimento sobre a prevenção e evolução da lesão nos trabal hadores brasileiros.

Revisando conceitos históricos sobre a doença, procuraremos citar a evolução do conhecimento científico no último século sobre o assunto os quais exerceram repercussões sobre as modificações das Leis e Normas que regulamentam as conseqüências sociais da doença.

\section{REVISÃO DE LITERATURA}

Os trabalhos científicos publicados até 1890 faziam descrições e observações apenas clínicas; pioneiramente, Habermann (1890) ${ }^{4}$ descreveu os achados anátomo-patol ógi cos detectados na cóclea e nervo coclear de caldeireiros. Verificou a característica das degenerações das cél ulas situadas na porção basal da cóclea.

Wittmack $(1907)^{5}$, foi o precursor dos estudos experimentais realizados com animais em laboratórios. Este autor descreveu a exposi ção de cobaias a ruídos breves e de alto nível de pressão sonora, estudando o resultado histopatológico.

F owler (1928) ${ }^{6}$ marcou o início das investigações com a utilização do audiômetro. Originou-se de seus estudos, a famosa Tabela de Fowler, adotada em nossa Legislação Trabalhista com a Portaria 3214 de 8/6/78.

Temkin $(1933)^{7}$ sugere a existência histofisiológica de uma zona de audibilidade situada na cóclea mais suscetível à ação do ruído.

Bunch $(1937)^{8}$ realiza um estudo no qual define as características auditivas e clínicas das disacusias induzidas pel o ruído em trabalhadores. Destaca a natureza insidiosa do problema e a característica da lesão que acomete mais gravemente a freqüência de $4000 \mathrm{~Hz}$ e a sua tendência de evolução atingindo outras freqüências circunvizinhas.

Observa que os limiares tendem a recuperar-se na freqüência de $8000 \mathrm{~Hz}$. Verifica que as freqüências graves, como $500 \mathrm{~Hz}$, não são afetadas e, quando ocorre tal fenômeno, a gravidade nunca atinge os níveis de $4000 \mathrm{~Hz}$. Conclui salientando sobre a necessidade de outros estudos referentes ao problema devido às implicações médico-legais que desencadeia, a fim de que o trabal hador receba um justo amparo legal e não se submeta apenas ao empirismo de advogados ou do empregador.
Este estudo marcou o final da década de 1930 nos Estados Unidos e é o r efl exo da inqui etação dos mei os científicos, jurídicos e sindicais da época em relação à prevenção da doença.

L arsen (1946) ${ }^{9}$ atri bui a um mecanismo de comprometimento da vascularização a lesão em $4000 \mathrm{~Hz}$.

Almeida (1950) ${ }^{10}$ fez um mapeamento de risco nos escritórios da estrada de F erro Sorocabana e, menci ona não apenas a lesão auditiva advinda da exposição ao ruído, mas destaca os efeitos estressantes deste agente. Correlaciona este fator com o absenteísmo na empresa.

Mocellin (1951)11 estuda vários casos de trabalhadores metalúrgicos expostos ao ruído e os analisa sob o aspecto clínico e auditivo. Não se limita à constatação da lesão, mas preocupa-se em algum tipo de prevenção do dano. Testa o uso de al godão vasel inado que é introduzido no conduto auditivo externo dos trabalhadores durante a jornada de trabalho e retesta-os audiometricamente após seis dias do uso, concluindo que houve melhora dos limiares.

Observa, também, que a legisl ação pertinente é de extrema importância, pois constitui forma de consci enti zação de trabal hadores e empregadores.

Suas conclusões evidenciam e refletem o problema epidemiológico que então se instalava em nosso meio. Dentre elas, a observação da alta incidência da doença em sua cidade; coloca a profilaxia do problema em primeira ordem e a necessidade de autoridades governamentais criarem um órgão técnico "a fim de pesquisar e prevenir a referida hipoacusia". Conclui ainda sobre a possível validade do uso de protetores auriculares durante a jornada. Solicita a atualização legislativa específica para proteção deste "sentido fundamental para a vida de relação".

A American Medical Association AMA (Council on Physical Medicine-1947) ${ }^{12}$ atribuiu porcentagens de importância as freqüências $500 \mathrm{~Hz}, 1000 \mathrm{~Hz}, 2000$ $\mathrm{Hz}$ e $4000 \mathrm{~Hz}$ com $15 \%, 30 \%, 40 \%$ e $15 \%$ respectivamente, para que o cál culo da incapacidade audi tiva fosse realizado levando-se em consideração o comprometimento social da recepção da fala.

A American Medical Association (Council on Physical Medicine and Rehabilitation-1955)13 determina os princípios de avaliação das perdas auditivas, mas não define fórmulas.

Gravendeel \& Plomp (1959) ${ }^{14}$ explicam a origem do termo $C^{5}$, declive que se origina do 5 - diapasão de teste e mel hora com o teste de $2000 \mathrm{~Hz}$ e $8000 \mathrm{~Hz}$. Estes autores indagam sobre a localização da lesão e sugerem que a perda maior possa ocorrer entre $2000 \mathrm{~Hz}$ e $4000 \mathrm{~Hz}$ ou entre $4000 \mathrm{~Hz}$ e $8000 \mathrm{~Hz}$. Ao verificarem 288 declives e fazer a distribuição gráfica destes, observam que há concentração de maiores perdas em $6000 \mathrm{~Hz}$. Não é realizada comparação com faixas etárias semel hantes, ignorando-se, 
neste trabal ho, o efeito da presbiacusia.

Harris, Haines, Myers (1960) ${ }^{15}$ destacam a importância dos limiares em $3000 \mathrm{~Hz}$ para compreensão da fala cotidiana.

O Commitee on Medical Rating of Physical Impairment $(1961)^{16}$ da AMA define a nova fórmula de avaliação das incapacitações incluindo apenas os limiares das freqüências de $500 \mathrm{~Hz}, 1000 \mathrm{~Hz}$ e $2000 \mathrm{~Hz}$.

Waal $\&$ Holland $(1961)^{17}$ estudaram 117 trabaIhadores metalúrgicos sendo que 107 deles apresentavam desvios de limiares de $15 \mathrm{~dB}$ ou mais nas freqüências de $1000 \mathrm{~Hz}$ a $8000 \mathrm{~Hz}$. Verificaram que $69 \%$ dos desvios permanentes de limiar estavam concentrados entre $3000 \mathrm{~Hz}$ e $6000 \mathrm{~Hz}$.

Glorig, Ward, Nixon $(1961)^{18}$ realizaram um estudo retrospectivo no qual foi verificada a evolução dos limiares em pelo menos três décadas de exposição comparativamente a uma população controle não exposta.

Observaram que o maior contingente de perdas instalam-se nos primeiros cinco anos de exposição e atingiram a freqüência de $4000 \mathrm{~Hz}$ principalmente. Com o passar dos anos, a lesão nesta freqüência não evolui tão rapidamente e as outras freqüências passam, então, a manifestar maior deterioração. Quando o ruído ambiental atinge níveis de pressão sonora mais intensos, o processo todo é acel erado. I sto é váli do para os níveis de pressão sonora maiores que $90 \mathrm{~dB}$.

Taylor et al. (1964) ${ }^{19}$ estudaram 251 trabal hadores aposentados que durante a sua vida ocupacional estiveram expostos a níveis de 99 a $102 \mathrm{~dB}$ SPL. Verificou deterioração da audição nos primeiros 10 a 15 anos de exposição seguidos por um período de 10 anos no qual a lesão atribuída ao ruído é pouco significativa, embora entre 20 e 25 anos de exposi ção sejam observadas degenerações dos limiares que atingem a freqüência de $2000 \mathrm{~Hz}$.

Atherley, Noble, Sugden (1967) ${ }^{20}$ estudaram metalúrgicos de fundição de ferro, bronze e manganês. Os limiares dos trabal hadores em $1000 \mathrm{~Hz}$, $2000 \mathrm{~Hz}, 3000 \mathrm{~Hz}$ e $6000 \mathrm{~Hz}$ é de 15 a 35 dB maiores que o dos outros grupos não expostos.

Marone (1968) ${ }^{21}$ realizou um estudo de revisão das disacusias ocupacionais, incluindo o trauma acústico ocupacional e a disacusia neuro-sensorial ocupacional por ruído.

Este autor disserta sobre as características da lesão audiométrica e clínica e propõe o uso da Tabela de Fowler como critério de avaliação da perda incapacitante funcionalmente.

Este trabalho exerceu grande influência em nosso meio, sendo adotado pel o Ministério do Trabalho, em 1978, os critérios de Fowler.

Atualmente, a Tabela deFowler, quejá foi utilizada nos Estados Unidos, apresenta apenas valor histórico.

Ward (1969) ${ }^{22}$ realiza um estudo sobre a evol ução auditiva de trabal hadores expostos ao ruído e verifica que a perda traduz-se por comprometimento predominante da freqüência de $4000 \mathrm{~Hz}$ embora verifique lesões máximas individuais isoladas em $3000 \mathrm{~Hz}$ e $6000 \mathrm{~Hz}$. Observa que com a evolução, o processo atinge as freqüências mais graves.

Miller (1972) $)^{23}$ observa, num estudo retrospecti vo, que grupos de trabalhadores com diferentes períodos de exposição ao ruído em anos apresentam perdas mais proeminentes em $4000 \mathrm{~Hz}$.

E stas alterações iniciais não seriam detectadas pelo próprio indivíduo. Com o aumento do tempo de exposição, outras freqüências seriam envolvidas incluindo $500 \mathrm{~Hz}$ a $3000 \mathrm{~Hz}$ com conseqüências danosas para a recepção da fala.

Clark \& Bohne (1978) ${ }^{24}$ expõem cricetos por 9 ou 18 dias a um ruído com bandas de oitavas centradas em $500 \mathrm{~Hz}$ com $95 \mathrm{~dB}$ SPL. Após este período, realizam avaliação histológi ca das células cocleares correlacionando os achados com a audiometria condicionada destes animais. Estes autores questionam postulados anteriores sobre a presença de uma curva assintótica indicando que a orelha encontra-se em estado de "equilíbrio" após um período de perda auditiva audiométrica rápida.

Observam que com o aumento do período de exposição de 9 para 18 dias, aumenta a probabilidade de lesão na região das altas freqüências cocleares e também há tendência ao aumento da severidade das lesões, enquanto que o dano celular às regiões apicais mantém-se constante.

Porém, não é constatada correl ação entre o dano celular observado e a sua manifestação auditiva.

E mbora os dados audiométricos sugerissem a existência de um "estado de equilíbrio", histol ogicamente não é observada a preservação celular, verificandose a evolução da destruição de células cilicadas.

Constata-se também que, apesar de a energia sonora concentrar-se nas baixas freqüências, as perdas permanentes ocorrem em altas freqüências, fato este atribuído à conformação do meato acústico externo humano e à sua ressonância, que favorece uma concentração de energia de cerca de $15 \mathrm{~dB}$ em $4 \mathrm{~K} \mathrm{~Hz}$ em relação as outras freqüências.

Concluem que é possível haver perda de células ciliadas externas de cerca de $20 \%$ na região apical sem afetar os limiares para os tons de baixas freqüências; há perda audiométrica para altas freqüências mesmo quando as lesões basais são pouco proeminentes e o declive em $4 \mathrm{KHz}$ foi produzido em cricetos com a exposição ao ruído de baixas freqüências. Este mesmo declive, que aparece em humanos, não é peculiar à exposição ao ruído.

Verificam que o audiograma simples e convencional pode não avaliar toda a condi ção de lesão cel ular da orelha interna. 
Pereira (1978) ${ }^{25}$ real iza um estudo epidemi ol ógi co em trabalhadores metalúrgicos. Propõe uma classificação da lesão em conformidade com o nível dos limiares. Observa que a prevalência de perda auditiva naquele grupo de trabal hadores era de $53,1 \%$.

Portaria 3214 de 8/6/78 do Ministério do TrabaIho-Brasil (1978) ${ }^{26}$ constitui um enorme avanço para a prevenção das doenças ocupacionais, incluindo as disacusias sensórioneurais ocupacionais por ruído.

Esta Portaria, através da Norma Regulamentadora $\mathrm{n}$ ㅇ 7, estabelece a obrigatoriedade dos exames audiométricos admissionais, periódicos e demissionais sempre que o ambiente de trabalho apresentar níveis de pressão sonora superiores a 85 dBA em 8 horas de exposição.

Estabel ece limites de exposição e diferencia ruídos contínuos e impulsivos.

Em sua Norma Regulamentadora $\mathrm{n} 015$ define também os critérios ambientais que caracterizam o trabal ho consi derado insalubre por exposi ção ao ruído.

Council on Scientific Affairs da AMA, (1979) ${ }^{27}$ inclui na avaliação da incapacidade auditiva a análise da freqüência de $3000 \mathrm{~Hz}$.

Environmental Health Criteria 12 - WHO (1980) ${ }^{1}$ congrega estudiosos de todo o mundo para discussão e publicação dos efeitos lesivos do ruído ambiental, incluindo o ambiente do trabal ho, na saúde do Homem.

Conclui que os governos devem adotar legisl ações modernas e, visto que se trata de um grave problema de saúde pública, alertar e orientar as comunidades.

Atherley \& J ohnston $(1983)^{28}$ consideram a disacusia por ruído como a doença ocupacional mais comum e questionam a validade da audiometria convencional para avaliar e classificar as lesões decorrentes desta doença.

Alberti (1982) ${ }^{29}$ considera a disacusia por ruído endêmica em várias partes do mundo e relata um caso onde, além da exposição ao ruído, há várias outras causas concomitantes de perda auditiva. Descreve a experiência da Seguridade Social em Ontário. Observa em sua casuística que $65 \%$ dos expostos apresentam história positiva de tinnitus além da perda auditiva.

Almei da (1985) ${ }^{30}$ estuda um caso de lesão auditiva de um trabalhador sob o aspecto clínico, procurando revelar fatores concomitantes que pudessem interferir com o ruído, abordando também os aspectos médicos-legais.

A autora estabelece a relação entre o ambiente ruidoso e a surdez; e entre a intensidade do ruído e a lesão, definindo-a como sensórioneural e bilateral. Conclui que na avaliação através do método de Fowler, o prejuízo auditivo mostra-se pouco significativo. Realiza propostas de controle audiométrico mesmo após a interrupção da exposição. Alerta que a detecção auditiva de desvios temporários de limiares podem re presentar um sinal precoce da suscetibilidade in- dividual de exposição ao ambiente ruidoso.

Cavalcanti, Rezende de Almeida, Butugan $(1985)^{31}$ realizam um levantamento clínico numa indústria metalúrgica; exami nam 123 trabalhadores com faixa etária entre 18 e 58 anos e tempo de exposição de 4 meses a 24 anos. Observaram que 82 trabalhadores $(66,66 \%)$ apresentam disacusia sensórioneural ocupacional por ruído. Além das perdas auditivas, verificaram que $72(47,05 \%)$ tinham queixa clínica de tinnitus.

$\mathrm{Na}$ casuística, a lesão predomina entre as freqüências de $3000 \mathrm{~Hz}$ a $6000 \mathrm{~Hz}$.

Axelsson \& Hamernik (1987) ${ }^{32}$ fazem uma revisão de 52 casos de trauma acústico ocupacional, nos quais há concomitânica das duas entidades clínicas da doença: a forma crôni ca de exposição ao ruído e a aguda. Destacam que o probl ema é pouco conhecido tanto pelos trabal hadores quanto pelos otorrinolaringologistas. Relatam o problema dos militares que estão constantemente expostos ao ruído impulsivo das armas de fogo.

Estes autores verificam que as queixas mais freqüentes são de hipoacusia seguida pelo tinnitus. Pode ser encontrada também a dor, hiperacusia e anestesia facial.

Estes casos se caracterizam por apresentaram três formas diferentes de audiograma: 76\% com ded ive na região de $5500 \mathrm{~Hz}$, declive dividido em $11 \%$ e, perda com queda abrupta em agudos em $13 \%$. A incapacidade que o trauma produz é significativa e, portanto, militares, mesmo que expostos por um breve período, podem apresentar deficiências significativas.

A manifestação audiométrica, porém, pode ser constatada após alguns anos do trauma agudo apenas através do exame audiométrico envolvendo altas freqüências acima de $8000 \mathrm{~Hz}$.

Este estudo adiciona-se a outros já citados que concluem que a audiometria convencional nem sempre é capaz de detectar as lesões decorrentes da exposição ao ruído.

Osguthorpe (1988) ${ }^{33}$ edita a publicação oficial da AAOHNS no qual o Subcomitee on the Medical Aspects of Noise delineia e atualiza toda a forma de controle e prevenção, assim como a avaliação dos critérios de incapacitação parcial da perda auditiva. Neste trabal ho discute-se o conceito de lesão auditiva e incapacitação auditiva.

Esta publicação orienta e padroniza as formas de abordagem Clínica e Médico-Legal que devem ser praticadas pelo médico.

Osguthorpe \& K lein (1989) ${ }^{34}$ detal ham, especificamente, o problema da disacusia neuro-sensorial por ruído e o trauma acústico ocupacional quanto à avaliação Médico-Legal. As normatizações propostas são os critérios mínimos adotados nos estados da Federação Norte-Americana. 
Clark \& Popelka (1989) ${ }^{35}$ realizam um estudo auditivo em 9427 ferroviários no qual são comparados aos limiares da população controle do apêndice B., preconizado pela Norma ISO 1999 (1990) ${ }^{36}$. Aplicam testes de análise de variância e verificam o efeito da evolução da idade. Concluem que ferroviários estudados por este método não diferem auditivamente da população.

Hetu, Quoc, Duguay (1990)33 aplicam as fórmulas preconizadas pela Norma ISO 1999 a uma população hipotética exposta a níveis de pressão sonora de 75 a 100 dB L eq e questionam a eficácia dos testes audiométricos convencionais com periodicidade anual para detecção das alterações de limiares permanentes.

Conraux (1990) ${ }^{37}$ define a disacusia por ruído ocupacional como "surdez de percepção, bilateral, sensivelmente simétrica embora discreta assimetria possa ser encontrada" e que atinge preferencialmente a freqüência de $4000 \mathrm{~Hz}$, estendendo-se então às demais freqüências. Considera que a fala social estará afetada quando a média aritmética dos limiares atingirem mais de $35 \mathrm{~dB}$ entre as freqüência de $500 \mathrm{~Hz}$ a $4000 \mathrm{~Hz}$. Destaca que estas afecção é irreversível e incurável e a sua profilaxia é o objeti vo principal. Recomenda a audiometria a cada seis meses como meio de controle.

Pela legislação francesa, a surdez profissional é reconhecida como doença no quadro 42 do regime federal. Este quadro, intitulado "afecções profissionais provocadas pelo ruído" foi aprovado em 4/ 5/1981 (J .O. 14/5/1981) pelo *decreto no 81-507. Por esta Lei, a doença é designada como lesão coclear bilateral, irreversível e que não se agrava após cessar a exposição ao risco.

Recomenda que a deficiência seja confirmada por novo exame audiométrico que deverá ser realizado de três semanas a um ano após a interrupção da exposição.

O prejuízo acarretado pela lesão é cal culado considerando-se os limiares na melhor orelha através da média ponderada das freqüências de $500 \mathrm{~Hz}, 1000 \mathrm{~Hz}$, $2000 \mathrm{~Hz}, 4000 \mathrm{~Hz}$ e multiplicando-se pel os coeficientes $2,4,3,1$, respectivamente, e deverá ser $>35 \mathrm{dBA}$.

As taxas de invali dez são estabel eci das utilizando-se as tabelas da surdez-doença.

Talbott et al. (1990) ${ }^{38}$ estudam limiares auditivos de 245 metalúrgicos trabalhadores aposentados de Pittsburgh, com idade entre 56-68, anos e com mais de 30 anos de exposição a ambientes ruidosos com níveis superiores a $89 \mathrm{dBA}$. Os resultados mostram que $52 \%$ do mais jovens, com idade entre 53 e 62 anos, apresentam perda auditiva classificada como severa, ou seja, $>65 \mathrm{dBA}$ em $3 \mathrm{KHz}, 4 \mathrm{KHz}$, ou $6 \mathrm{KHz}$ enquanto esta proporção aumentava para $67 \%$ dos mais vel hos. São estudados índices de discriminação em ambiente ruidoso e houve correlação negativa entre os grupos com perda severa e hipertensão arterial. Em relação aos limiares, constatam que se apresentam dentro dos limites normais até $1000 \mathrm{~Hz}$ seguindo-se por uma progressão de perda que começa por um declínio de 12 dBA entre $1000 \mathrm{~Hz}$ e $2000 \mathrm{~Hz}$, um declínio de 30 dBA entre $2000 \mathrm{Hze} 3000 \mathrm{~Hz}$ quepiora entre $3000 \mathrm{Hze} 6000$ $\mathrm{Hz}$ e, finalmente, uma leve recuperação em $8000 \mathrm{~Hz}$.

Os testes monossilábicos de discriminação vocal administrados em áreas sil enciosas estão, em quase $100 \%$ da amostra, dentro do normal. Mas quando os mesmos testes são realizados com ruído de fundo, há diminuição dos índices com piora de cerca de $20 \%$. Estes autores não fazem comparações com os padrões audiométricos normais para as respectivas faixas etárias.

Phaneuf \& Hetu (1990) $)^{39}$, através de estudos epidemiológicos, verificam que a disacusia sensórioneural por ruído é a doença ocupacional mais prevalente. Suas estimativas são de que a inci dência seja de 8 a 12/1000 pessoas, consi drando-se que a prevalência total de perdas auditivas é de 77/ 1000 para homens e 70/1000 para mulheres.

Quanto aos efeitos da exposição ocupacional ao ruído, estes autores referem que a extensão de lesão de pessoas expostas é observada, audiometricamente, como rapidamente progressiva, diminuindo o seu ritmo de progressão após alguns anos. A diferença entre um grupo de indivíduos expostos ao ruído e um não-exposto inicia-se em zero, atinge um máximo e subsequentemente declina.

$O$ efeito inicial manifesta-se na deterioração de $4 \mathrm{KHz}$, atingindo $3000 \mathrm{~Hz}$ e $6000 \mathrm{~Hz}$. O declive audiométrico, causado pelo declínio em $4000 \mathrm{~Hz}$, aumenta rapidamente, evolui para um achatamento da curva devido à "desaceleração" do efeito do ruído, época na qual 3000 e $6000 \mathrm{~Hz}$ atinge os níveis semel hantes aos de $4000 \mathrm{~Hz}$.

Devido à deterioração de $6000 \mathrm{~Hz}$ com a idade, altera-se a forma do audiograma de um declive para um declínio progressivo, que o distingue de pessoas não-expostas e que mantiveram limiares melhores de $500 \mathrm{~Hz}$ a $2000 \mathrm{~Hz}$.

Para estes autores, a relação entre ruído e idade não são adicionais. De acordo com os estudos da ISO 1999( 1990), os efeitos da idade e ruído são aditivos até a soma de ambos atingir $40 \mathrm{~dB}$.

Vincent, F raysse, E stève-Fraysse $(1990)^{40}$ classificam a disacusia por exposição ao ruído como um processo irreversível, progressivo e sugerem que controles através da audiometria de altas freqüências entre $8000 \mathrm{~Hz}$ e $18000 \mathrm{~Hz}$ e a pesquisa das oto-

\footnotetext{
* Decreto no 81-507 Apud Conraux, C. Surdités Profissionelles, La Revue du Praticien, 40(19):1762-5, 1990.
} 
emissões acústicas poderão detectar mais precocemente o aparecimento de lesões em pacientes de risco, enquanto que o audiograma convencional ainda se encontra inalterado.

Úlehlová, Branis, J anisch (1990) ${ }^{41}$ estudam os ossos temporais de 41 minei ros com lesão audi ológica de diversas severidades, com idade variando de 38 a 74 anos. Destes 41 casos, seis foram selecionados para serem comparados com os achados audiométricos de testes realizados entre duas semanas até três anos antes do óbito. Todos os seis ossos são expostos a ambientes ruidosos durante a vida ocupacional. Realiza-se contagem completa de células ciliadas de um extremo ao outro da membrana basilar. É observado que nos ossos temporais estudados havia áreas detotal destruição do órgão de Corti atingindo a parte basal da membrana basilar, não acima de $14 \mathrm{~mm}$ da base coclear. Estes achados questionam a noção comum de que a destruição do epitélio do órgão de Corti resultará em perda auditiva tonotópica ao local da lesão.

Considerando a relação tonotópica da Membrana Basal são evidênciadas três lesões ao redor de $4 \mathrm{KHz}$, duas lesões em $10 \mathrm{KHz}$ e $6 \mathrm{KHz}$ e uma lesão em $3 \mathrm{KHz}$. Concluíram que a região mais vulnerável está em $4 \mathrm{KHz}$.

Axelsson \& Hamernik (1987) ${ }^{32}$ e Hanner \& Axelsson (1988) ${ }^{42}$ encontram que tanto o trauma acústico quanto a disacusia induzida por ruído afetam as freqüências agudas na seguinte ordem: $6 \mathrm{KHz}, 4 \mathrm{KHz}, 8 \mathrm{KHz}, 3 \mathrm{KHz}, 1 \mathrm{KHz}$.

Riko et al. (1990) ${ }^{43}$ consideram a exposição ocupacional ao ruído como a principal causa de disacusia sensórioneural com a conseqüente invalidez parcial para os trabalhadores. A reabilitação ocorre através da adaptação de prótese auditiva. The Workers Compensation Board em Ontário (WCBO) assume a responsabilidade pelas reabilitações nos casos em quea disacusia tem perda de $25 \mathrm{dBA}$ ou mais nas freqüência de $500 \mathrm{~Hz}, 1000 \mathrm{~Hz}, 2000 \mathrm{~Hz}, 3000 \mathrm{~Hz}$ em cada orel ha ou quando a perda for de $35 \mathrm{~dB}$ ou mais em uma orelha, podendo ser inferior a $25 \mathrm{dBA}$ na outra. Este processo é descentralizado e o WCBO paga os custos aos serviços comunitários. Neste estudo retrospectivo, referente à reabilitação, foram atendidos 3509 trabalhadores num período de 10 anos. A média de idade era de 56,4 anos, $98,7 \%$ do sexo masculino e o tempo médio de exposição de 25 anos. Os limiares por freqüências em ambas as orel has são estudados e foi aplicada a classificação de Goodman Scale of Hearing I mpairment que é a seguinte:

$\begin{array}{lll}\text { Normal } 0|-| 15 \mathrm{~dB} & \text { Leve } 16|-| 40 \\ \text { Moderada } 41|-| 50 & \text { severa }>55\end{array}$

Observam que há predominância de perdas simétricas, bilaterais, leves ou moderadas (61\%).

Concluem que todos os graus de perdas ocorrem nos reclamantes e $90 \%$ dos que realizam rea- bilitação beneficiam-se do uso das próteses.

Lim \& Stephens (1991) ${ }^{44}$, ao estudarem a prevalência de perdas auditivas relaci onadas com o idoso, encontram como fatores responsáveis pelas queixas $11,25 \%$ de disacusias por exposição ou ruído.

Norma ISO 1999 (1990) ${ }^{36}$ atribui uma forma de cálculo para a previsão de risco de perda auditiva à população exposta, de acordo com a faixa etária e exposição, segundo o nível de pressão sonora equivalente contínuo - Leq de 8 horas diárias de exposição. Além da atribuição do risco, determina a perda auditiva de uma popul ação otol ogicamente normal não-exposta ao ambiente ruidoso.

Almeida (1991) ${ }^{45}$ discute e revê o diagnóstico diferencial da disacusia sensórioneural ocupacional por ruído e destaca que esta doença necessita de uma avaliação clínica otorrinolaringológica e que o diagnóstico não deverá limitar-se à análise isolada de limiares audiométricos. São revistas doenças sistêmicas e otológicas que acarretam lesão na orelha interna.

\section{Objetivos do trabalho}

1. Caracterização quanto às queixas clínicas auditivas e aos limiares audiométricos de uma popul ação de trabal hadores brasil eiros expostos a níveis de pressão sonora em ambiente de trabalho superiores a 85 dBA para uma exposição diária mínima de 8 horas. 2. Relacionar os desvios de limiares por freqüência da audiometria tonal, faixa etária e tempo em anos de exposição.

3. Comparar os desvios de limiar por freqüência, anos de exposi ção efaixa etária com o risco apresentado pela norma ISO 1999 para uma população controle, sem antecedente de doença auditiva e que sofreu apenas a deterioração decorrente da idade. 4. Fornecer subsídios técni cos para as avaliações dos casos individuais.

\section{MATERIAL E MÉTODO}

Foi realizado um estudo retrospectivo em 222 casos classificados como "Surdez Profissional" induzida pela exposição ao ruído, de acordo com o CID 388.1 (classificação internacional das doenças).

E $m$ todos os casos, tratavam-se de trabalhadores do sexo masculino que foram encaminhados ao Serviço Médico de Saúde do Trabal hador pertencente ao Serviço Social da Indústria (SESI), em Vila Leopoldina, São Paulo.

Todos os pacientes eram submetidos à exame clínico completo que se iniciava com anamnese profissional detalhada descrevendo a atividade exercida e especificando os agentes agressores existentes no ambiente de trabalho.

Estas informações eram seguidas por anamnese 
clínica, na qual se exploravam possíveis queixas de origem otológica como hipoacusia, tinnitus, tonturas.

A história clínica era concluída com o interrogatório sobre diversos aparel hos (ISDA), antecedentes mórbidos e hábitos.

Após, realizava-se exame clínico completo e o paciente era encaminhado para aval iação auditiva, antes da qual o audiologista preenchia um questionári o detal hado sobre a exposição ao ruído quanto ao tempo em anos (esta variável foi verificada por duas vezes: pelo médico e pelo audiologista). Para que o trabal hador realizasse a avaliação auditiva, exigia-se um período de repouso acústic o mínimo de 14 horas, ou seja, afastamento do ambiente ruidoso durante este período mínimo.

Todos os exames foram realizados em ambiente com condições acústicas normatizadas internacionalmente e por profissional audiologista. Foi empregado para os testes audiológi cos Audiômetro marca Amplaid 207 e Impedanciômetro Amplaid 702, ambos calibrados de acordo com os padrões ANSI .

Considerou-se requisito obrigatório para participação no estudo que a curva timpanométrica estivesse normal. Não foram analisados os casos de trauma acústico ocupacional agudo.

Com estes dados, construímos tabelas e gráficos, nos quais relacionamos a faixa etária, tempo de exposição ao ruído e limiares audiométricos. Devi do ao caráter bilateral das lesões, optamos por estudar o limiar na mel hor orelha.

A amostra foi di vidida de acordo com o tempo de exposição em quatro categorias: (Tabelas 1 e 3)

grupo 1: $\leq 10$ anos de exposição ao ruído grupo 2: 11 - 15 anos de exposição ao ruído grupo 3: 16 - 20 anos de exposição ao ruído grupo 4: $\geq 21$ anos de exposição ao ruído

A divisão da $2^{\text {a }}$ década de exposi ção em partes foi realizada devido ao maior número de trabalhadores que foram atendidos nesta fase de evolução do processo, tornando assim um período de interesse para o estudo da doença.

Cada um destes grupo foi subdividido de acordo com a faixa etária, resultando nos seguintes agrupamentos, conforme a Tabela 1 .

grupo 1-1: faixa etária até 39 anos $\leq 10$ anos de exposição

grupo 1-2: faixa etária até 39 anos 11 - 15 anos de exposi ção

grupo 1-3: faixa etária até 39 anos 16 - 20 anos de exposi ção

grupo 1-4: faixa etária até 39 anos $\geq 21$ anos de exposição

grupo 2-1: faixa etária 40 - 49 anos $\leq 10$ exposição ao ruído

grupo 2-2: faixa etária 40 - 49 anos 11 - 15 exposição ao ruído

\begin{tabular}{|c|c|c|c|}
\hline \multirow[b]{2}{*}{$\begin{array}{l}\text { Tempo de } \\
\text { exposição }\end{array}$} & \multicolumn{2}{|c|}{ Faixa etária } & \multirow[b]{2}{*}{$\geq 50$} \\
\hline & até 39 anos & $40-49$ & \\
\hline$\leq 10$ & Grupo 1-1 & Grupo 2-1 & Grupo 3-1 \\
\hline $11|-| 15$ & Grupo 1-2 & Grupo 2-2 & Grupo 3-2 \\
\hline $16|-| 20$ & Grupo 1-3 & Grupo 2-3 & Grupo 3-3 \\
\hline$\geq 21$ & Grupo 1-4 & Grupo 2-4 & Grupo 3-4 \\
\hline
\end{tabular}

grupo 2-3: faixa etária 40 - 49 anos 16 - 20 exposição ao ruído

grupo 2-4: faixa etária 40 - 49 anos $\geq 21$ anos de exposição ao ruído

grupo 3-1 faixa etária $\geq 50$ anos de idade $\leq 10$ anos de exposição

grupo 3-2 faixa etária $\geq 50$ anos de idade 11 - 15 anos de exposição

grupo 3-3 faixa etária $\geq 50$ anos de idade 16 - 20 anos de exposição

grupo 3-4 faixa etária $\geq 50$ anos de idade $\geq 21$ anos de exposição

Devido ao insignificante número de casos, não foram anali sados os grupos 3-1, 3-2, 1-4 que tinham 1,1 e quatro casos, respectivamente, assim como não se realizaram gráficos para os grupos 3-3 e 2-1.

As tabelas 2 e 3 mostram onúmero de casos em cada grupo com suas respectivas médi as de idade e desvios padrões, assim como a média dos anos de exposição ao ruído, desvios padrões e atividade profissional.

Calculamos a média dos limiares audiométricos com os respectivos desvios padrões para cada grupo, considerando-se sempre a mel hor orel ha do trabal hador. Os valores obtidos estão contidos na Tabela 4.

Utilizando a idade média de cada grupo da amostra (Tabela 2) e tomando-a como parâmetro para o cál culo dos limiares audiométri cos de uma população controle otologicamente normal e sem história ocupacional de exposição ao ruído, conforme o preconizado pela norma ISO 1999 (1990) ${ }^{36}$, calculamos os limiares esperados para os percentis 10,50 e 90 desta população nas freqüênci as de 250 $\mathrm{Hz}$ a $8000 \mathrm{~Hz}$. Os val ores obtidos estão na tabela 5 .

F oram realizados gráficos para cada grupo que continham os seguintes dados:

1-Valor do limiar audiométrico esperado por freqüência dos percentis 10, 50 e 90 da população controle para a média de idade encontrada no respectivo grupo amostral;

2-Valor do limiar médio por freqüência para o grupo estudado;

3- Desvios padrões por freqüência para cada grupo estudado.

Para análise estatística destes grupos foram utilizados testes de Anál ise de Variância com del imitação de intervalos de confiança de Tukey, teste de X 


\begin{tabular}{|c|c|c|c|c|c|}
\hline \multirow{2}{*}{\multicolumn{2}{|c|}{$\begin{array}{c}\text { Tamanho } \\
\text { Grupo da amostra }\end{array}$}} & \multicolumn{2}{|c|}{ Idade } & \multicolumn{2}{|c|}{ Tempo de exposição } \\
\hline & & Média aritmética & Desvio padrão & Média aritmética & Desvio padrão \\
\hline $1-1$ & 32 & 32.13 & 5.375 & 6.13 & 2.756 \\
\hline $1-2$ & 41 & 34.90 & 2.719 & 13.24 & 1.428 \\
\hline $1-3$ & 29 & 35.55 & 2.443 & 17.38 & 1.208 \\
\hline $2-1$ & 6 & 43.33 & 2.805 & 8.67 & 2.338 \\
\hline $2-2$ & 20 & 42.35 & 2.368 & 13.50 & 1.469 \\
\hline $2-3$ & 36 & 42.92 & 2.335 & 18.61 & 1.440 \\
\hline $2-4$ & 30 & 43.73 & 2.924 & 24.1 & 1.989 \\
\hline $3-3$ & 6 & 52.50 & 2.345 & 17.00 & 1.549 \\
\hline $3-4$ & 16 & 56.13 & 4.272 & 25.13 & 4.241 \\
\hline
\end{tabular}

Tabela 3 - Freqüências (número de pessoas na amostra) das profissões para cada grupo - Ramo de profissão

\begin{tabular}{|lccccccccc}
\hline & \multicolumn{7}{c|}{ Grupo } \\
\cline { 2 - 8 } Ramo de Profissão & $1-1$ & $1-2$ & $1-3$ & $2-1$ & $2-2$ & $2-3$ & $2-4$ & $3-3$ & $3-4$ \\
Metalurgia & 23 & 34 & 25 & 6 & 16 & 34 & 22 & 5 & 10 \\
Gráfica & 0 & 1 & 0 & 0 & 0 & 0 & 0 & 0 & 3 \\
Têxtil & 2 & 0 & 0 & 0 & 0 & 0 & 0 & 0 & 1 \\
Alimentação & 1 & 0 & 0 & 0 & 0 & 0 & 0 & 0 & 1 \\
Química & 0 & 0 & 0 & 0 & 0 & 1 & 1 & 0 & 0 \\
Carpintaria & 2 & 0 & 0 & 0 & 1 & 0 & 0 & 0 & 0 \\
Não especificado & 4 & 6 & 4 & 0 & 3 & 1 & 7 & 1 & 1 \\
Total & $\mathbf{3 2}$ & $\mathbf{4 1}$ & $\mathbf{2 9}$ & $\mathbf{6}$ & $\mathbf{2 0}$ & $\mathbf{3 6}$ & $\mathbf{3 0}$ & $\mathbf{6}$ & $\mathbf{1 6}$ \\
\hline
\end{tabular}

Tabela 4 - Média dos limiares audiométricos e respectivos desvios padrões para cada grupo e para cada freqüência.

\begin{tabular}{|c|c|c|c|c|c|c|c|c|c|c|c|c|c|c|c|c|}
\hline \multirow[b]{3}{*}{ Grupo } & & & \multicolumn{14}{|c|}{ Freqüências (Hertz) } \\
\hline & \multicolumn{2}{|c|}{250} & \multicolumn{2}{|c|}{500} & \multicolumn{2}{|c|}{1000} & \multicolumn{2}{|c|}{2000} & \multicolumn{2}{|c|}{3000} & \multicolumn{2}{|c|}{4000} & \multicolumn{2}{|c|}{6000} & \multicolumn{2}{|c|}{8000} \\
\hline & Média & $\begin{array}{l}\text { Desv. } \\
\text { Padr. }\end{array}$ & Média & $\begin{array}{l}\text { Desv. } \\
\text { Padr. }\end{array}$ & Média & $\begin{array}{l}\text { Desv. } \\
\text { Padr. }\end{array}$ & Média & $\begin{array}{l}\text { Desv. } \\
\text { Padr. }\end{array}$ & Média & $\begin{array}{l}\text { Desv. } \\
\text { Padr. }\end{array}$ & Média & $\begin{array}{l}\text { Desv. } \\
\text { Padr. }\end{array}$ & Média & $\begin{array}{l}\text { Desv. } \\
\text { Padr. }\end{array}$ & Média & $\begin{array}{l}\text { Des. } \\
\text { Padr. }\end{array}$ \\
\hline $1-1$ & 17.73 & 8.50 & 14.84 & 7.24 & 14.22 & 8.81 & 17.50 & 13.32 & 28.36 & 14.26 & 37.66 & 14.08 & 35.55 & 17.28 & 28.91 & 20.39 \\
\hline $1-2$ & 22.07 & 10.25 & 18.66 & 10.73 & 17.20 & 12.55 & 25.73 & 17.27 & 42.74 & 15.06 & 52.20 & 13.04 & 52.20 & 15.00 & 39.15 & 19.55 \\
\hline $1-3$ & 18.28 & 8.69 & 15.00 & 9.16 & 14.31 & 11.08 & 23.97 & 13.72 & 38.02 & 15.77 & 45.52 & 11.75 & 44.22 & 18.86 & 32.76 & 21.32 \\
\hline $2-1$ & 18.33 & 9.31 & 14.17 & 6.65 & 14.17 & 6.65 & 15.00 & 8.94 & 30.00 & 10.95 & 42.50 & 7.58 & 42.08 & 6.00 & 32.50 & 21.62 \\
\hline $2-2$ & 20.25 & 8.66 & 18.50 & 9.05 & 17.75 & 13.23 & 25.25 & 15.85 & 39.63 & 15.71 & 51.50 & 16.07 & 45.13 & 18.65 & 33.75 & 21.45 \\
\hline $2-3$ & 25.13 & 8.33 & 19.03 & 9.84 & 23.19 & 13.64 & 31.94 & 17.33 & 46.94 & 18.46 & 54.03 & 14.18 & 52.85 & 22.00 & 44.72 & 24.93 \\
\hline $2-4$ & 18.92 & 5.86 & 16.33 & 6.01 & 17.50 & 9.35 & 27.67 & 15.18 & 39.83 & 16.25 & 48.17 & 15.51 & 49.33 & 18.93 & 38.50 & 20.73 \\
\hline $3-3$ & 14.17 & 3.76 & 11.67 & 5.16 & 22.50 & 11.73 & 32.50 & 17.54 & 47.50 & 15.08 & 50.00 & 15.49 & 46.67 & 25.43 & 31.67 & 30.44 \\
\hline $3-4$ & 21.88 & 9.46 & 21.88 & 11.81 & 25.31 & 16.58 & 38.13 & 18.15 & 48.75 & 14.89 & 54.69 & 13.22 & 59.06 & 21.77 & 49.38 & 24.49 \\
\hline
\end{tabular}

Quadrado para análise de queixa clínica otológica. F oram real izados vários ti pos de gráficos para atingir o objetivo de comparar os parâmetros col etados entre os grupos e entender a evolução da doença nos diversos grupos etários e nos diferentes períodos de exposição. (M otta Singer \& Andrade, 1986) ${ }^{46}$.

\section{RESULTADOS}

\section{Queixas Clínicas}

Verificamos que em todos os grupos, exceto no grupo 1-1, foi maior o número de queixas de hipoacusia em relação a tinnitus (Tabela 6).

Testou-se a hipótese de independência entre os grupos e a queixa clínica contra a hipótese alternativa de que haveria dependência.

E $m$ todos os casos, exceto tinnitus por tempo de exposição, a hipótese nula de independência foi rejeitada.

\section{Análise dos limiares audiométricos por freqüência}

Foram elaborados gráficos comparativos ( 1 a 7 ) entre os limiares da população em estudo com os seus respectivos desvios padrões e os percentis 10, 50 e 90 de uma população controle sem lesão otológica.

Para estudar se existiam diferenças entre os limiares segundo a freqüência, faixa etária e tem- 


\begin{tabular}{|c|c|c|c|c|c|c|c|c|c|}
\hline \multirow{2}{*}{$\begin{array}{l}\text { Idade } \\
\text { média } \\
\text { (anos) }\end{array}$} & \multicolumn{8}{|c|}{ Freqüência (Hertz) } & \multirow[b]{2}{*}{8000} \\
\hline & Percentil & 250 & 500 & 1000 & 2000 & 3000 & 40000 & 6000 & \\
\hline 32 & $\begin{array}{l}10 \\
50 \\
90\end{array}$ & $\begin{array}{c}9.47 \\
0.59 \\
-6.53\end{array}$ & $\begin{array}{c}8.93 \\
0.69 \\
-5.90\end{array}$ & $\begin{array}{c}9.08 \\
0.78 \\
-5.84\end{array}$ & $\begin{array}{c}11.42 \\
1.37 \\
-6.66\end{array}$ & $\begin{array}{c}13.51 \\
2.25 \\
-6.76\end{array}$ & $\begin{array}{c}15.62 \\
3.14 \\
-6.85\end{array}$ & $\begin{array}{c}17.66 \\
3.53 \\
-7.77\end{array}$ & $\begin{array}{c}20.31 \\
4.31 \\
-8.49\end{array}$ \\
\hline 35 & $\begin{array}{l}10 \\
50 \\
90\end{array}$ & $\begin{array}{c}9.91 \\
0.87 \\
-6.37\end{array}$ & $\begin{array}{c}9.43 \\
1.01 \\
-5.72\end{array}$ & $\begin{array}{c}9.66 \\
1.16 \\
-5.64\end{array}$ & $\begin{array}{c}12.45 \\
2.02 \\
-6.31\end{array}$ & $\begin{array}{c}15.19 \\
3.32 \\
-6.18\end{array}$ & $\begin{array}{c}17.95 \\
4.62 \\
-6.04\end{array}$ & $\begin{array}{c}20.28 \\
5.20 \\
-6.86\end{array}$ & $\begin{array}{c}23.52 \\
6.36 \\
-7.38\end{array}$ \\
\hline 37 & $\begin{array}{l}10 \\
50 \\
90\end{array}$ & $\begin{array}{c}10.25 \\
1.08 \\
-6.26\end{array}$ & $\begin{array}{c}9.83 \\
1.26 \\
-5.58\end{array}$ & $\begin{array}{c}10.11 \\
1.44 \\
-5.48\end{array}$ & $\begin{array}{c}13.24 \\
2.53 \\
-6.04\end{array}$ & $\begin{array}{c}16.49 \\
4.15 \\
-5.73\end{array}$ & $\begin{array}{c}19.76 \\
5.78 \\
-5.41\end{array}$ & $\begin{array}{c}22.32 \\
6.50 \\
-6.16\end{array}$ & $\begin{array}{c}26.01 \\
7.94 \\
-6.52\end{array}$ \\
\hline 42 & $\begin{array}{l}10 \\
50 \\
90\end{array}$ & $\begin{array}{c}11.26 \\
1.73 \\
-5.91\end{array}$ & $\begin{array}{c}11.01 \\
2.02 \\
-5.17\end{array}$ & $\begin{array}{c}11.46 \\
2.30 \\
-5.02\end{array}$ & $\begin{array}{c}15.60 \\
4.03 \\
-5.22\end{array}$ & $\begin{array}{c}20.38 \\
6.62 \\
-4.39\end{array}$ & $\begin{array}{c}25.17 \\
9.22 \\
-3.54\end{array}$ & $\begin{array}{l}28.40 \\
10.37 \\
-4.06\end{array}$ & $\begin{array}{l}33.44 \\
12.67 \\
-3.94\end{array}$ \\
\hline 43 & $\begin{array}{l}10 \\
50 \\
90\end{array}$ & $\begin{array}{c}11.5 \\
11.88 \\
-5.83\end{array}$ & $\begin{array}{c}11.3 \\
2.19 \\
-5.08\end{array}$ & $\begin{array}{c}11.8 \\
2.50 \\
-4.91\end{array}$ & $\begin{array}{r}16.1 \\
4.38 \\
-5.03\end{array}$ & $\begin{array}{c}21.3 \\
7.19 \\
-4.08\end{array}$ & $\begin{array}{c}26.4 \\
10.00 \\
-3.11\end{array}$ & $\begin{array}{c}29.8 \\
11.25 \\
-3.60\end{array}$ & $\begin{array}{c}35.1 \\
13.75 \\
-3.36\end{array}$ \\
\hline 52 & $\begin{array}{l}10 \\
50 \\
90\end{array}$ & $\begin{array}{c}14.00 \\
3.47 \\
-4.96\end{array}$ & $\begin{array}{c}14.20 \\
4.05 \\
-4.07\end{array}$ & $\begin{array}{c}15.11 \\
4.62 \\
-3.76\end{array}$ & $\begin{array}{l}21.98 \\
8.092 \\
-3.01\end{array}$ & $\begin{array}{l}30.85 \\
13.29 \\
-0.76\end{array}$ & $\begin{array}{c}39.74 \\
18.50 \\
1.50\end{array}$ & $\begin{array}{c}44.80 \\
20.81 \\
1.62\end{array}$ & $\begin{array}{c}53.48 \\
25.43 \\
2.99\end{array}$ \\
\hline \multirow[t]{2}{*}{56} & $\begin{array}{l}10 \\
50\end{array}$ & $\begin{array}{c}15.35 \\
4.33\end{array}$ & $\begin{array}{c}15.78 \\
5.05\end{array}$ & $\begin{array}{c}16.92 \\
5.78\end{array}$ & $\begin{array}{l}25.14 \\
10.11\end{array}$ & $\begin{array}{l}36.05 \\
16.61\end{array}$ & $\begin{array}{l}46.97 \\
23.10\end{array}$ & $\begin{array}{l}52.94 \\
25.99\end{array}$ & $\begin{array}{l}63.43 \\
31.77\end{array}$ \\
\hline & 90 & -4.49 & -3.52 & -3.13 & -1.92 & 1.04 & 4.01 & 4.44 & 6.44 \\
\hline
\end{tabular}

\begin{tabular}{|ccc|}
\hline \multicolumn{3}{|c|}{ Tabela 6 - Porcentagens de queixas por grupos. } \\
\hline Grupo & Hipoacusia & Tinnitus \\
$1-1$ & 0.19 & 0.25 \\
$1-2$ & 0.49 & 0.39 \\
$1-3$ & 0.62 & 0.28 \\
$2-1$ & 0.83 & 0.50 \\
$2-2$ & 0.55 & 0.25 \\
$2-3$ & 0.67 & 0.28 \\
$2-4$ & 0.57 & 0.27 \\
$3-3$ & 0.83 & 0.50 \\
$3-4$ & 0.75 & 0.31 \\
Total & $\mathbf{0 . 5 5}$ & $\mathbf{0 . 3 1}$ \\
\hline
\end{tabular}

po de exposição, foi utilizada a análise U nivariada de Perfis (Modelo Univariado) para os Grupos 1-1, 1-2, 1-3, 2-2, 2-3, 2-4 e 3-4.

Verificamos que os grupos da 2a década de exposição (1-2, 1-3, 2-2, 2-3) apresentaram interação entre idade e tempo de exposição $(p=0,0039)$, ou seja, o comportamento dos limiares para os dois grupos de idade testados não é o mesmo, variando conforme o tempo de exposição ao ruído.

Para verificarmos entre quais grupos ocorria diferença foi feito o gráfico de intervalos de confiança de Tukey (95\%) para as médias de limiares dos grupos de idade e observamos que para o grupo com tempo de exposição de 16 - 20 anos os limiares dos < 39 apresentavam-se diferentes do grupo de 40 - 49 .
Não foi observada interação estatística entre freqüência, faixa etária e tempo de exposição que se traduz através do comportamento paralelo das curvas, como se constata através dos gráficos.

Para todos os grupos verificamos o "Efeito Hertz", ou seja, a média dos limiares das diferentes freqüências não são iguais, que se traduz audiometricamente através da falta de horizontalidade da curva. Clinicamente, não se observa uma pancocleopatia, pois as freqüências não são acometidas com a mesma intensidade.

\section{Estudo da discriminação vocal}

Estudamos o índice de discriminação vocal convencional para palavras foneticamente balanceadas monossilábicas, $40 \mathrm{dBA}$ acima do limiar (Tabela 7).

Os testes estatísticos revelaram interação entre a idade e o tempo de exposi ção $(p=0,0027)$ indicando que a discriminação vocal altera-se conforme haja mudanças nestes parâmetros.

\section{DISCUSSÃO}

\section{Primeira década de exposição ao ruído.}

Nosso estudo revel a que os trabal hadores que têm até 10 anos de exposição ao ruído poderão apresentar perda auditiva instalada, porém facilmente detectada através do exame audiométrico convencional.

Neste grupo, a lesão encontra-se num estágio inicial, mas os danos detectados são irreversíveis, 


\begin{tabular}{|cccccc|}
\hline \multicolumn{5}{|c|}{ Tabela 7 } & Discriminação vocal média e respectivos desvios padrões por grupo. \\
\hline Grupo & $\begin{array}{c}\text { Tamanho } \\
\text { de amostra }\end{array}$ & Média & $\begin{array}{c}\text { Desvios } \\
\text { Padrões }\end{array}$ & Intervalos de confiança de 95\% \\
$1-1$ & 27 & 94.814815 & 5,30 & 91.427521 & 98.202109 \\
$1-2$ & 39 & 89.384615 & 9,89 & 86.566217 & 92.203014 \\
$1-3$ & 23 & 93.826087 & 6,52 & 90.156047 & 97.496127 \\
$2-1$ & 5 & 90.400000 & 10,43 & 82.528640 & 98.271360 \\
$2-2$ & 18 & 92.000000 & 6,86 & 87.851429 & 96.148571 \\
$2-3$ & 32 & 87.625000 & 10,33 & 84.513572 & 90.736428 \\
$2-4$ & 27 & 88.962963 & 8,97 & 85.575669 & 92.350257 \\
$3-3$ & 6 & 90.000000 & 13,33 & 82.814465 & 97.185535 \\
$3-4$ & 14 & 92.000000 & 10,98 & 87.295963 & 96.704037 \\
Total & 191 & 90.816754 & 8,92 & 89.543198 & 92.090310 \\
\hline
\end{tabular}

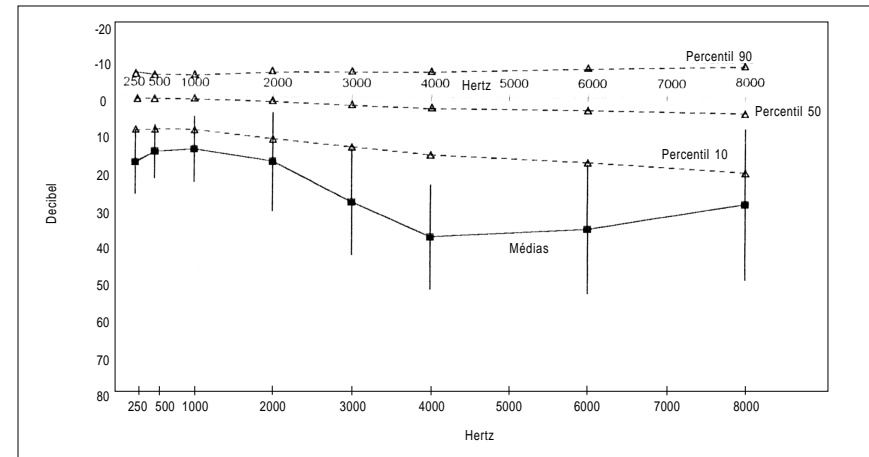

Gráfico 1 - Médias de limiares, desvios padrões, limiares dos percentis 10,50 e 90 da população controle. Grupo 1-1 ( 39 anos deidadee até 10 anos deexposi ção ao ruído).

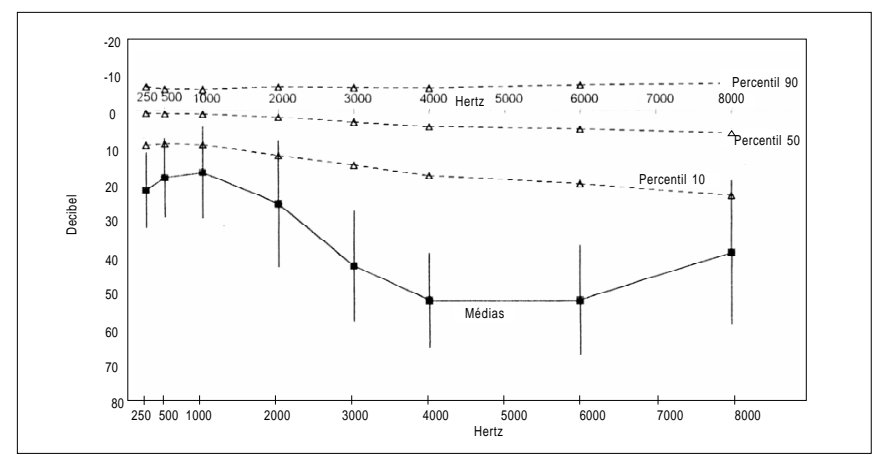

Gráfico 2 - Médias, desvios padrões, percentis 10,50 e 90. Grupo 1-2 ( $\leq 39$ anos de idade e tempo de exposição de 11 a 15 anos).

como observamos na evolução da doença dos grupos que se sucedem.

Clinicamente, encontramos uma menor freqüência de queixas auditivas sendo que a tinnitus tem maior incidência que a queixa de hipoacusia. O mais comum foi a ausência de qualquer queixa auditiva.

Conraux (1990) ${ }^{37}$ relata que após alguns dias de exposição já se observa alteração audiométrica em $4000 \mathrm{~Hz}$, mas não considerou nesta avaliação os desvios temporários de limiares,comuns de serem detectados em qualquer indivíduo exposto ao ruído. Observa que a queixa clínica ocorre muito tardiamente, por vezes, apenas às vésperas de uma apo-

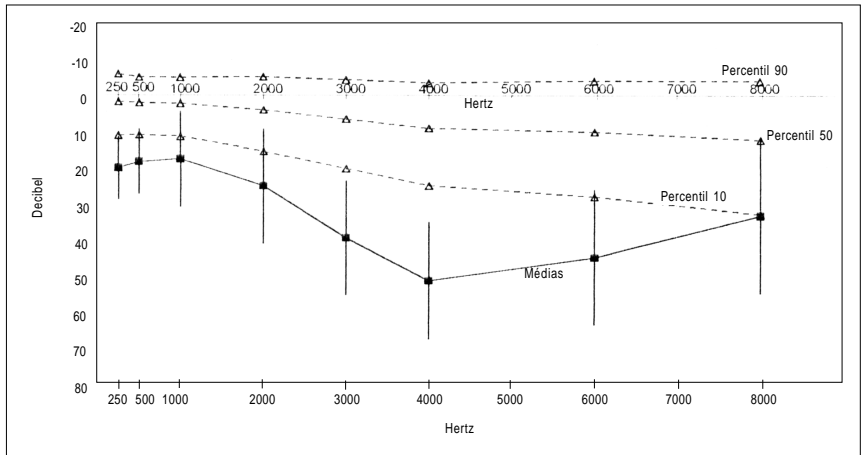

Gráfico 3 - Médias, desvios padrões, percentis 10,50 e 90. Grupo 2-2 (40 /-/ 49 anos de idade e tempo de exposição de 11 a 15 anos)

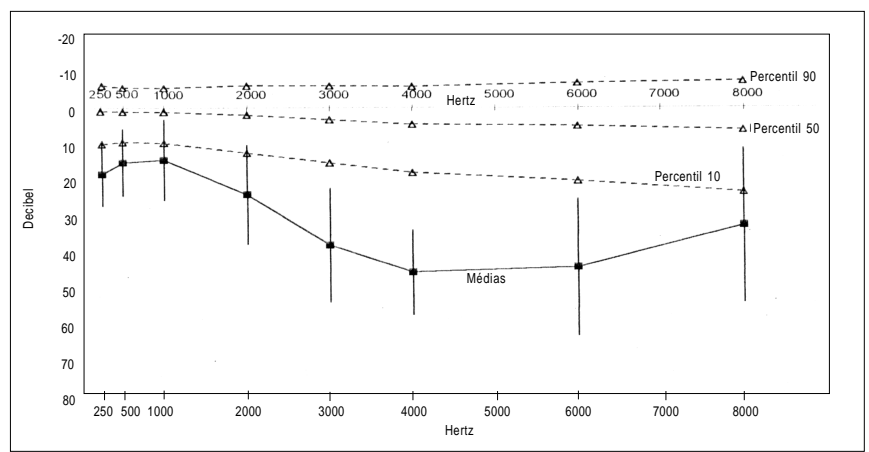

Gráfico 4 - Médias, desvios padrões, percentis 10, 50 e 90. Grupo 1-3 ( $\leq 39$ anos de idade e tempo de exposição de 16 a 20 anos).

sentadoria. Descreve um primeiro estado de latência clínica completa, chamada de fase pré-patogênica da curva audiométrica de período variável.

WHO (1980); Caval canti, Rezende de Almei da , Butugan (1986) ${ }^{31}$ observam que os sintomas clínicos iniciais da disacusia sensórioneural ocupacional por ruído não são detectados pel o trabal hador.

Hetu, Quoc , Duguay (1990) ${ }^{3}$ chamam a atenção para a dificul dade de detecção destas perdas auditivas nos primeiros anos de exposição devido à lentidão da instalação da perda permanente.

Em nossa casuística, a proporção de queixa de hipocausia aumenta com a evolução do tempo de 


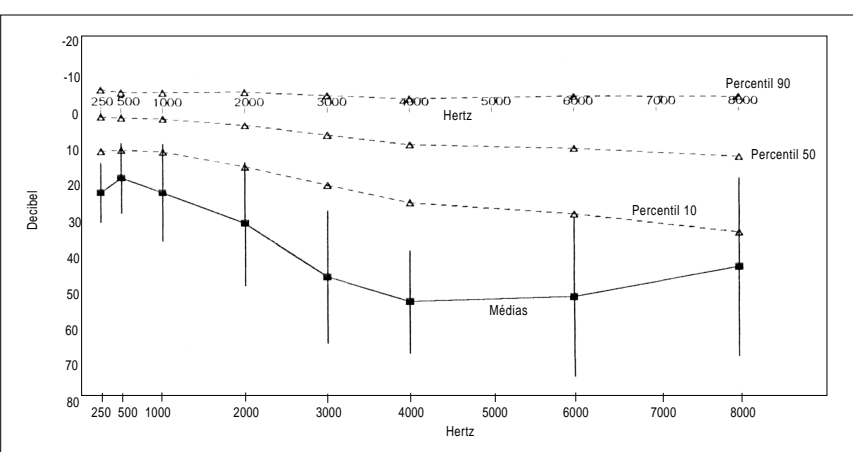

Gráfico 5 - Médias, desvios padrões, percentis 10, 50 e 90. Grupos 2-3 (40 /-/ 49 anos de idade e tempo de exposição de 16 a 20 anos).

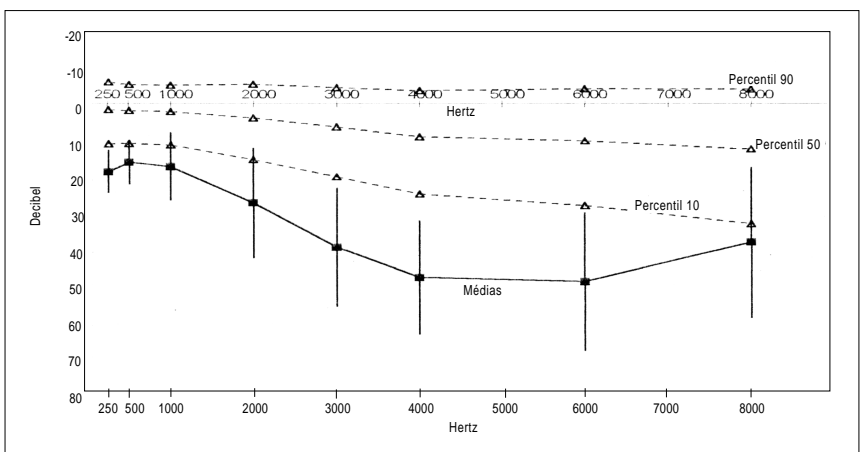

Gráfico 6 - Médias, desvios padrões, percentis 10, 50 e 90. Grupo 2-4 (40/-/ 49 anos de idade e acima de 20 anos de exposição).

exposição e da idade, enquanto que o tinnitus, como queixa, mostrou-se menos específico, pois não seconstatou relação com o tempo de exposição mas com a faixa etária, tendendo a predominar nos mais jovens.

Pialoux (1974) ${ }^{47}$ descreve que nas primeiras jornadas em que há exposição ao ruído, os fenômenos clínicos são extremamente subjetivos. Após, haveria um período de latência que equivale à instalação da lesão em $4000 \mathrm{~Hz}$. O tinnitus aparece nessa fase. Somente após anos, instala-se a disacusia e esta queixa é a mais provável de ser encontrada no indivíduo de cerca de 40 anos.

Nosso estudo revela que na primeira década de exposição apenas cerca de $30 \%$ dos indivíduos terão queixa clínica de disacusia e/ou tinnitus, sendo que este irá predominar nos mais jovens. E mbora já sejam detectadas as alterações de limiares audiométricos, a queixa hipoacusia apresenta menor incidência que o tinnitus.

Mocellin (1950) ${ }^{11}$ relata que a queixa de hipoacusia pode ser o único sintoma que faz com que o trabalhador chegue ao médico.

Quanto à evolução dos limiares, pudemos observar que a lesão inicia-se afetando gravemente 4000 $\mathrm{Hz}$ e evolui atingindo as freqüências circunvizinhas.

$\mathrm{N}$ a primeira década há comprometimento inicial da freqüência de $4000 \mathrm{~Hz}$, seguida por $6000 \mathrm{~Hz}$.

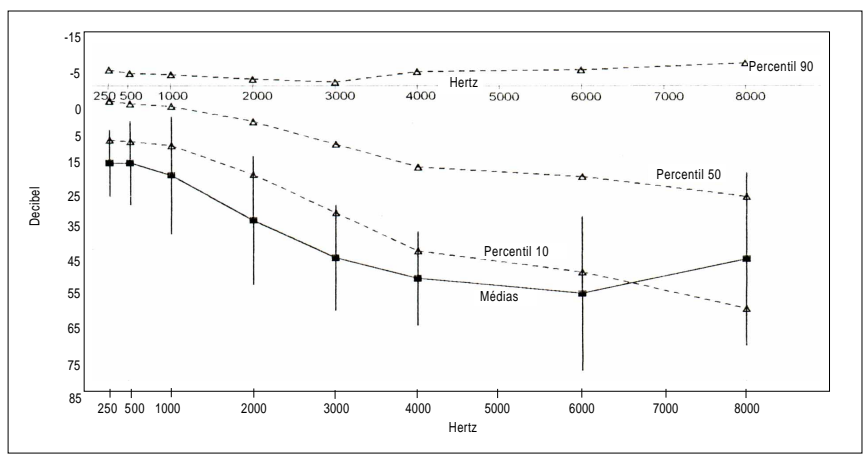

Gráfico 7 - Médias, desvios padrões, percentis 10, 50 e 90. Grupo 3-4 ( $\geq 50$ anos) de idade e mais de 20 anos de exposi ção.

As freqüências de $3000 \mathrm{~Hz}$ e $8000 \mathrm{~Hz}$, embora se afastem da curva normal, não apresentam diferenças estatisticamente significantes entre ambas.

Ao analisarmos o gráfico, observamos que as médias dos limiares de $2000 \mathrm{~Hz}$ e $3000 \mathrm{~Hz}$ desviamse da curva controle em seu percentil 10, mas não provocam alteração significativa suficientemente para interferir na recepção de fala, justificando a baixa incidência da queixa de hipoacusia.

Temkin (1933) ${ }^{7}$, Clark \& Bohne $(1978)^{24}$ destacaram a existência de uma região coclear que seria mais suscetível à lesão provocada pel o ruído. Esta zona seria a região correspondente à freqüência de $4000 \mathrm{~Hz}$.

Nossa casuística, nesta primeira década de exposição, caracterizou-se pela lesão mais pronunciada em $4000 \mathrm{~Hz}$ concordante com os estudos clínicos de Ward (1969) ${ }^{22}$, Bunch (1973) ${ }^{8}$, Miller (1972) ${ }^{23}$, Waal (1961)17, e os estudos experimentais de Ulehlová, Branis, J anisch $(1990)^{40}$ e Clark \& Bohne (1978) ${ }^{24}$, que reproduziram a lesão em $4000 \mathrm{~Hz}$.

O trabalho de Harris, Haines, Meyers $(1960)^{15}$ é decisivo para destacar a importância do comprometimento da freqüência de $3000 \mathrm{~Hz}$ e a conseqüente repercussão para a compreensão da fala cotidiana. Verificamos, em nossa casuística, que ambos os grupos (1-1 e 2-1), que possuem o mesmo tempo de exposição, mas diferem na faixa etária, tem limiares semel hantes em sua média aproximada em $3000 \mathrm{~Hz}$ $(=30 \mathrm{dBA})$ e as diferenças nas médias da discriminação vocal não são estatisticamente significantes, corroborando os achados destes autores.

Observamos que a partir dos 40 anos (grupo 21) há tendência à piora dos limiares nas freqüências mais agudas em relação ao grupo mais jovem. O índice de discriminação vocal convencional acompanhou esta tendência.

Analisando o gráfico para o grupo 1-1, verificamos que os val ores médios de limiares atéa freqüência de $2000 \mathrm{~Hz}$ apresentam-se compreendidos entre os percentuais 90 e 10, não diferindo do grupo controle.

A partir de $3000 \mathrm{~Hz}$ observa-se piora dos limiares com progressivo afastamento dos valores nor- 
mais que se acentuam em $4000 \mathrm{~Hz}$; há pequena melhora em $6000 \mathrm{~Hz}$ e recuperação em $8000 \mathrm{~Hz}$.

Observamos que a média e desvios padrões do limiar da freqüência $4000 \mathrm{~Hz}$ estão nitidamente afastados do percentil 10 em ambos os grupos analisados e há grande variabilidade dos dados individuais na freqüência de $6000 \mathrm{~Hz}$.

Cavalcanti, Rezende de Almeida, Butugan $(1986)^{31}$ ressal tam o papel da variabilidade individual, mas a constância da lesão em $4000 \mathrm{~Hz}$ mantém-se concordante com os dados de WHO (1980). Ward (1969) ${ }^{22}$ também constatou, em seu estudo de evol ução audi tiva, perdas entre $3000 \mathrm{~Hz}$ e $6000 \mathrm{~Hz}$, mas a perda máxima ocorre em $4000 \mathrm{~Hz}$.

Phaneuf \& Hetu (1990) ${ }^{39}$ referem que a primeira alteração mais comumente detectada está em 4000 $\mathrm{Hz}$, mas, pode também ocorrer em $3000 \mathrm{~Hz}$ e $6000 \mathrm{~Hz}$.

E m nosso estudo, no grupo 1-1 ( $<39$ anos e $<10$ anos de exposição), houve diferença estatisticamente significante entre os limiares de todas as freqüências exceto entre $3000 \mathrm{~Hz}$ e $8000 \mathrm{~Hz}$, que se encontram igualmente afetadas.

Portanto, podemos inferir que nos primeiros 10 anos de exposição a freqüência que mais está comprometida é $4000 \mathrm{~Hz}$, sendo seguida por $6000 \mathrm{~Hz}$. Não há diferença entre as médias de limiares de $8000 \mathrm{~Hz}$ e $3000 \mathrm{~Hz}$ e estas duas freqüências seguem em terceiro lugar quanto ao comprometimento. 10 $4000 \mathrm{~Hz} ; 206000 \mathrm{~Hz} ;$ 3 $3000 \mathrm{~Hz}=8000 \mathrm{~Hz}$

Os limiares médios aproximados para as freqüências testadas no grupo 1-1 são:

$$
\begin{array}{rlrl}
250 \mathrm{~Hz} & \rightarrow 20 \mathrm{dBA} & 500 \mathrm{~Hz} & \rightarrow 15 \mathrm{dBA} \\
1000 \mathrm{~Hz} & \rightarrow 15 \mathrm{dBA} & 2000 \mathrm{~Hz} \rightarrow 20 \mathrm{dBA} \\
3000 \mathrm{~Hz} & \rightarrow 30 \mathrm{dBA} & 4000 \mathrm{~Hz} & \rightarrow 40 \mathrm{dBA} \\
6000 \mathrm{~Hz} & \rightarrow 35 \mathrm{dBA} & 8000 \mathrm{~Hz} \rightarrow 30 \mathrm{dBA}
\end{array}
$$

Podemos considerar que estas são médias de limiares esperadas para indivíduos até 39 anos de idade e até 10 anos de exposição em ambiente industrial ruidoso, os quais são portadores de disacusia sensórioneural ocupacional.

\section{Segunda década de exposição ao ruído Grupos 1-2, 2-2, 1-3, 2-3}

É na segunda década de exposição que encontramos o maior contingente de indivíduos da amostra: 126 trabalhadores (grupos 1-2, 1-3, 2-2, 2-3) ou seja, 56\%. Observamos que na segunda década não houve diferenças significativas de limiares entre os grupos 1-2 e 2-2, mas pela análise estatística de multivariância, encontrou-se diferença entre os grupos 1-3 e 2-3 os quais, embora apresentem tempo de exposi ção semel hante, di ferem pela faixa etária. O comprometimento dos li miares reflete-se no índice de discriminação vocal que se apresenta pior no grupo de maior idade.
Ainda, através da análise de multivariância, não observamos diferença estatisticamente significante entre as freqüências $4000 \mathrm{~Hz}$ e $6000 \mathrm{~Hz}$, encontrando ambas no mesmo nível de acometimento. Verificamos que, assim como na primeira década, há grande número de indi víduos nos quais não houve relato de queixa auditiva.

Almeida (1985) ${ }^{30}$ observa em seu estudo clínico que mesmo após 17 anos de exposição ao ruído, o trabalhador foi manifestar queixa auditiva apenas após episódio gripal no qual instalou-se uma lesão mista em uma das orel has.

Indivíduos mais jovens ( $<39$ anos) ao entrarem na segunda década de exposição, passam a ter, em cerca de $50 \%$ dos casos, queixa de hipoacusia e ao entrarem na segunda metade da primeira década este índice sobe para 62\%. Há dificuldade instalada par o entendimento da linguagem falada: é o sinal de "cocktail party".

A partir de então, as al terações de limiares começam a desencadear manifestações clínicas que farse-ão presentes à anamnese, sendo que a queixa de hipoacusia predomina enquanto que o tinnitus mantém uma incidência quase que constante.

Bunch (1937) ${ }^{8}$ observa que nem sempre o tinnitus está presente. Alberti (1982) ${ }^{29}$ relata que $65 \%$ dos reclamantes com perda auditiva ocupacional apresentam tinnitus.

Caval canti, Rezende de Almeida, Butugan (1986) ${ }^{31}$ observam que $47,05 \%$ de sua amostragem eram portadores de tinnitus.

Marone (1968) ${ }^{21}$ ressalta que tinnitus pode ser o único sintoma presente e até mais incômodo que a própria surdez. Resultaria de vibração de células cicatriciais localizadas no local onde houve perda de células ciliadas. A hipoacusia pode passar desapercebida, segundo este autor. Relata que encontrou incidência de $25 \%$ em pesquisa nos ambientes de trabalho ruidosos.

Embora com alguma variação entre as faixas etárias, através de nossa casuística constatamos que no início da segunda década de exposi ção (grupos 12 e 2-2) há um aumento significativo da inci dência da queixa de hipoacusia em relação a primeira década de exposição. É neste período que a população procura um atendimento médico especializado. Observase que a recepção da fala passa a sofrer a interferência da diminuição dos limiares auditivos.

No grupo 1-2 notamos que a queixa otológica clínica de hipoacusia ocorre em $49 \%$ dos casos enquanto que tinnitus incide em $39 \%$.

No grupo 1-3, de faixa etária mais avançada, há um nítido aumento da freqüência de queixa de hipoacusia com $62 \%$ de incidência enquanto que o tinnitus mantém $28 \%$ de incidência. 


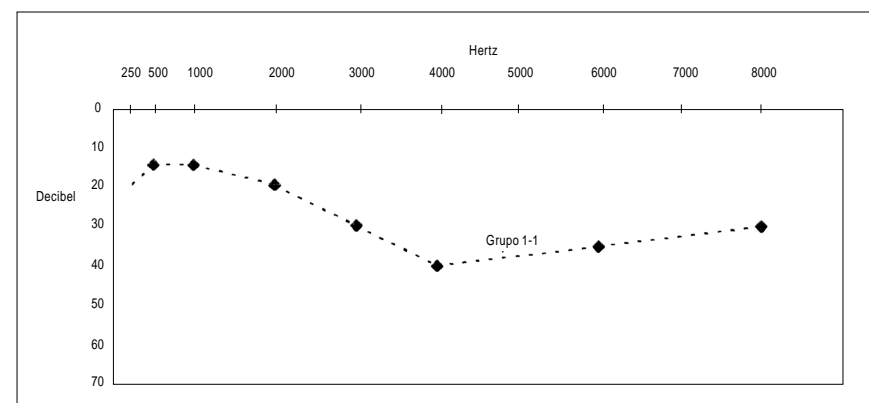

Gráfico 8 - Parâmetros médios de perdas auditivas para indivíduos com até 10 anos de exposição ao ruído e $\leq 39$ anos de idade.

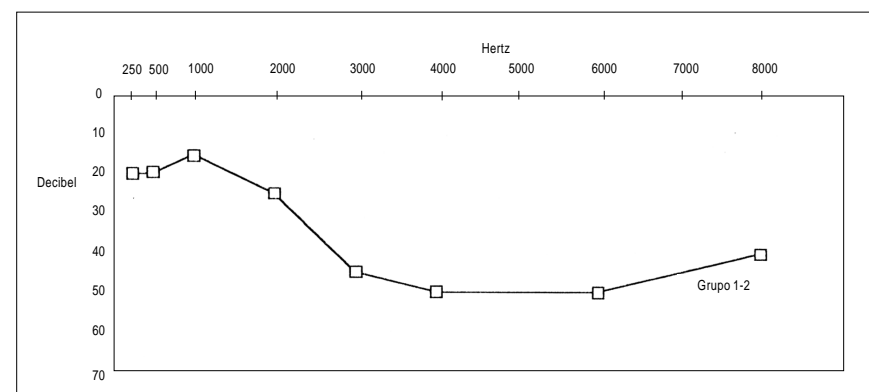

Gráfico 9 - Parâmetros médios de perdas auditivas para indi víduos com 11 a 15 anos de exposição ao ruído e $\leq 39$ anos de idade.

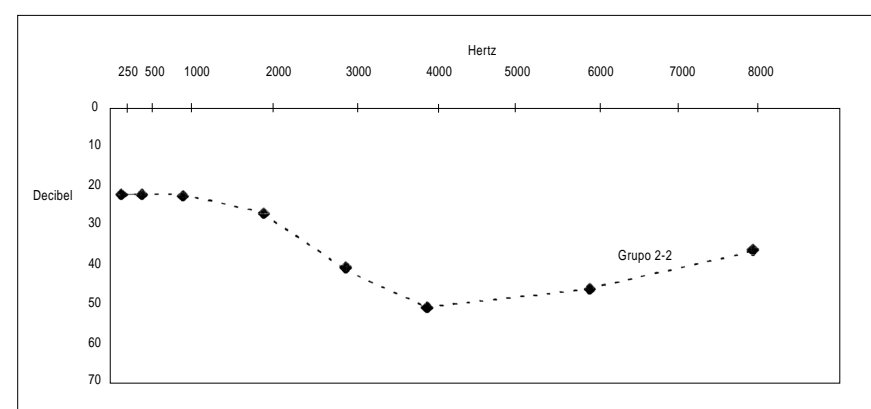

Gráfico 10 - Parâmetros médios de perda auditiva para indi víduos com tempo de exposi ção ao ruído de 16 a 20 anos e com idade compreendida entre 40 /- / 49 anos.

No grupo 2-2 a hipoacusia apresenta freqüência de $55 \%$ e tinnitus de $25 \%$.

No grupo 2-3 há a seguinte incidência: $67 \%$ de hipoacusia e $28 \%$ de tinnitus. Observamos que nos grupos de faixa etária maior e com mais tempo de exposição,a queixa de hipoacusia torna-se freqüente, acometendo cerca de $2 / 3$ dos indivíduos afetados pela perda ao audiograma.

Este é um grupo no qual, com grande chance, o paciente nos trará uma queixa ou, mesmo quando não encaminhado, procurará o serviço médico espontaneamente. A piora da lesão em $3000 \mathrm{~Hz}$ justifica o aumento da incidência da queixa clínica. Quando analisamos os quatro grupos da segunda década de exposição, verificamos que outros autores observaram que a freqüência mais afetada

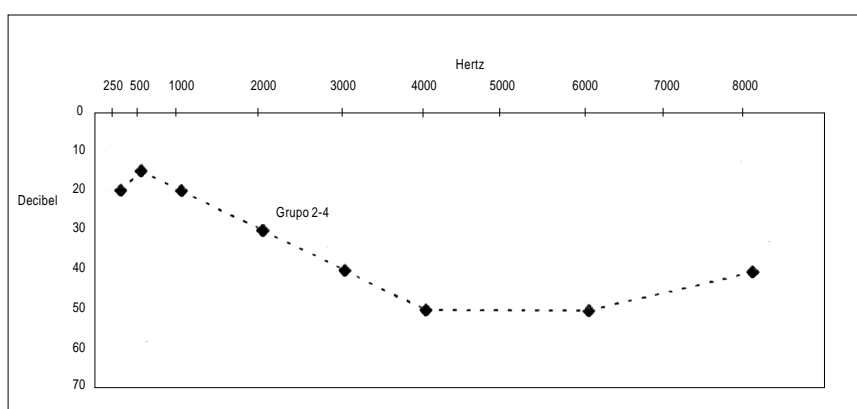

Gráfico 11 - Parâmetros médios de perda auditiva para indi víduos com mais de 20 anos de tempo de exposi ção ao ruído e com idade compreendida entre 40 /- / 49 anos.

é $4000 \mathrm{~Hz}$, concordante com os nossos resultados. E m grupos com maior idade e com mai or tempo de exposi ção, a freqüência de $6000 \mathrm{~Hz}$ atinge os mesmos níveis de $4000 \mathrm{~Hz}$ e não se observa diferença estatisticamente significante entre ambas.

L arsen $(1946)^{9}$ destaca em seu estudo o comprometimento da lesão em $4000 \mathrm{~Hz}$. Gravendell \& Plomp (1959) ${ }^{14}$ observaram que a lesão seria mais acentuada em $6000 \mathrm{~Hz}$, assim como Axelsson \& Hamernik (1987)32e Hanner \& Axelsson (1988) ${ }^{42}$.

Ward (1969) ${ }^{22}$ considera que a freqüência mais lesada é $4000 \mathrm{~Hz}$, assim como Conraux (1990) ${ }^{37}$.

Portanto, na segunda década, a lesão se espaIha e atinge $6000 \mathrm{~Hz}$ de forma mais pronunciada. Os limiares de $6000 \mathrm{~Hz}$ chegam aos níveis de 4000 $\mathrm{Hz}$ e, $3000 \mathrm{~Hz}$ é mais afetada que $8000 \mathrm{~Hz}$ sendo que estas freqüências passam a ter diferenças significantes.

As freqüências mais graves também manifestam o efeito da exposição. A partir da segunda metade da segunda década de exposição, começamos a observar as diferenças entre os grupos etários até 39 anos e entre 40 e 49 anos.

A freqüência $4000 \mathrm{~Hz}$ apresenta menor desvio padrão com pontos concentrados próximos à média, o que configura a constância e estabili dade de lesão nesta freqüência.

A queda em $4000 \mathrm{~Hz}$ evolui rapidamente e depois há um período de estabilização. As freqüências de $3000 \mathrm{~Hz}$ e $6000 \mathrm{~Hz}$ passam a ser mais afetadas com $6000 \mathrm{~Hz}$, atingindo os valores de $4000 \mathrm{~Hz}$ primeiramente e, depois, ocorrendo o mesmo com $3000 \mathrm{~Hz}$. Devido à deterioração de 6 $\mathrm{KHz}$ com a idade, o audiograma tende a assumir a forma em U. A lesão dissemina-se em todo o audiograma.

E m nossa casuística, os grupos 1-2, 1-3, 2-2, 2-3 foram analisados mantendo-se a metodologia de multivariância e verificamos que para os quatro grupos há diferenças entre as médias dos limiares de cada freqüência, exceto $4000 \mathrm{~Hz}$ e $6000 \mathrm{~Hz}$.

Este dado confirma a tendência de evolução da 


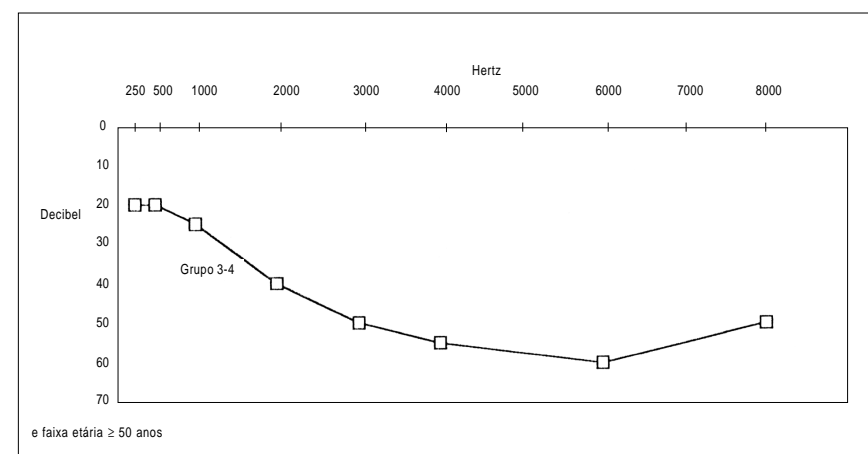

Gráfico 12 - Parâmetros de perda auditiva para indivíduos com mais de 20 anos de tempo de exposi ção ao ruído.

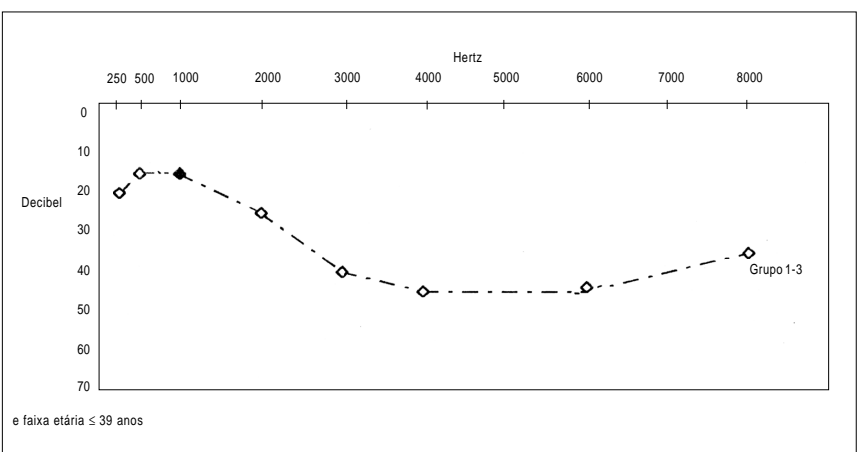

Gráfico 13 - Parâmetros de perda auditiva para indivíduos com tempo de exposição ao ruído entre 16 e 20 anos e faixa etária $\leq 39$ anos.

lesão com alteração inicial de $4000 \mathrm{~Hz}$ que se estende a $6000 \mathrm{~Hz}$ sendo que esta freqüência tende a sofrer as conseqüências da lesão nos mesmos níveis de $4000 \mathrm{~Hz}$. Os limiares em $3000 \mathrm{~Hz}$, são piores que os de $8000 \mathrm{~Hz}$.

A evolução de lesão é contínua e mantém a sua tendência original durante a segunda década:4000 $\mathrm{Hz}=6000 \mathrm{~Hz}$; a segunda freqüência mais afetada é $3000 \mathrm{~Hz}$ e, em terceiro lugar, estaria $8000 \mathrm{~Hz}$

\section{Os limiares médios aproximados para o gru-} po 1-2 são:

$\begin{array}{rlrl}250 \mathrm{~Hz} & \rightarrow 20 \mathrm{dBA} & 500 \mathrm{~Hz} & \rightarrow 20 \mathrm{dBA} \\ 1000 \mathrm{~Hz} & \rightarrow 15 \mathrm{dBA} & 2000 \mathrm{~Hz} & \rightarrow 25 \mathrm{dBA} \\ 3000 \mathrm{~Hz} & \rightarrow 45 \mathrm{dBA} & 4000 \mathrm{~Hz} & \rightarrow 50 \mathrm{dBA} \\ 6000 \mathrm{~Hz} & \rightarrow 50 \mathrm{dBA} & 8000 \mathrm{~Hz} \rightarrow 40 \mathrm{dBA}\end{array}$

Os limiares médios aproximados para o grupo 2-2:

$\begin{array}{rlrl}250 \mathrm{~Hz} & \rightarrow 20 \mathrm{dBA} & 500 \mathrm{~Hz} & \rightarrow 20 \mathrm{dBA} \\ 1000 \mathrm{~Hz} & \rightarrow 20 \mathrm{dBA} & 2000 \mathrm{~Hz} & \rightarrow 25 \mathrm{dBA} \\ 3000 \mathrm{~Hz} & \rightarrow 40 \mathrm{dBA} & 4000 \mathrm{~Hz} \rightarrow 50 \mathrm{dBA} \\ 6000 \mathrm{~Hz} \rightarrow 45 \mathrm{dBA} & 8000 \mathrm{~Hz} \rightarrow 35 \mathrm{dBA}\end{array}$

Os limiares médios aproximados para o grupo 1-3:

$\begin{array}{rlrl}250 \mathrm{~Hz} & \rightarrow 20 \mathrm{dBA} & 500 \mathrm{~Hz} & \rightarrow 15 \mathrm{dBA} \\ 1000 \mathrm{~Hz} & \rightarrow 15 \mathrm{dBA} & 2000 \mathrm{~Hz} & \rightarrow 25 \mathrm{dBA} \\ 3000 \mathrm{~Hz} & \rightarrow 40 \mathrm{dBA} & 4000 \mathrm{~Hz} \rightarrow 45 \mathrm{dBA} \\ 6000 \mathrm{~Hz} \rightarrow 45 \mathrm{dBA} & 8000 \mathrm{~Hz} \rightarrow 35 \mathrm{dBA}\end{array}$

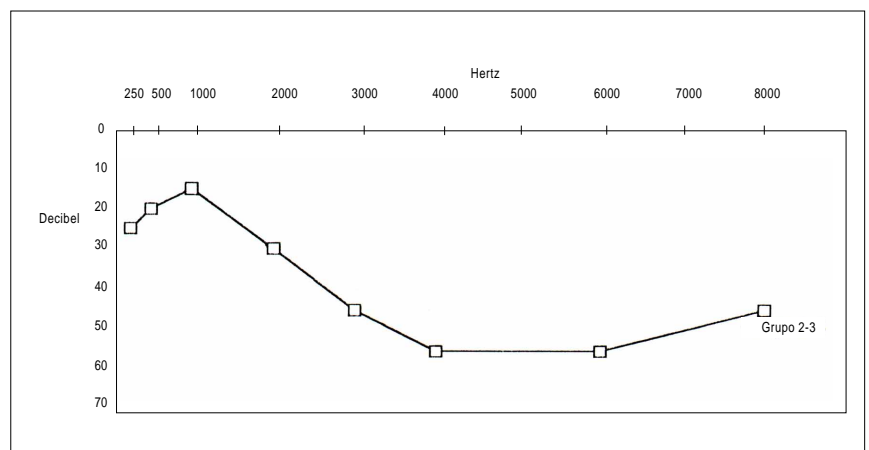

Gráfico 14 - Parâmetros de perda auditiva para indivíduos com tempo de exposi ção ao ruído compreendido entre 16 e 20 anos e faixa etária de 40 /- / 49 anos.

Os limiares médios aproximados para o grupo 2-3:

$$
\begin{aligned}
250 \mathrm{~Hz} & \rightarrow 25 \mathrm{dBA} \\
1000 \mathrm{~Hz} & \rightarrow 15 \mathrm{dBA} \\
3000 \mathrm{~Hz} & \rightarrow 45 \mathrm{dBA} \\
6000 \mathrm{~Hz} & \rightarrow 55 \mathrm{dBA}
\end{aligned}
$$

$$
\begin{aligned}
500 \mathrm{~Hz} & \rightarrow 20 \mathrm{dBA} \\
2000 \mathrm{~Hz} & \rightarrow 30 \mathrm{dBA} \\
4000 \mathrm{~Hz} & \rightarrow 55 \mathrm{dBA} \\
8000 \mathrm{~Hz} & \rightarrow 45 \mathrm{dBA}
\end{aligned}
$$

\section{Terceira década}

\section{Grupos 2-4 e 3-4}

A pesar do predomínio absoluto de metalúrgicos, notamos maior diversificação de atividades tais como carpintaria, têxtil, alimentícia. A média de idade do grupo 3-4 é de 56 anos e o tempo de exposição médio é de 25 anos.

Observamos que o comprometimento $4000 \mathrm{~Hz}$ e $8000 \mathrm{~Hz}$ não diferem si gnificativamente de $3000 \mathrm{~Hz}$ :

$4000 \mathrm{~Hz}=8000 \mathrm{~Hz}=6000 \mathrm{~Hz}$

$8000 \mathrm{~Hz}=3000 \mathrm{~Hz}$

Verificamos que estas freqüências estão profundamente afetadas. E ste fato reflete-se na incidência da queixa clínica hipoacusia que é de $75 \%$ e da tinnitus de $31 \%$.

No grupo 2-4 a freqüência de queixa otológica de hipoacusia é de $57 \%$ e tinnitus de $27 \%$. No terceiro estágio da disacusia sensórioneural ocupacional por ruído há dificuldade para a compreensão da fala nas circunstâncias normais de vida. Observamos que neste período a média entre os limiares das freqüências de $2000 \mathrm{~Hz}, 1000 \mathrm{~Hz}$ e $500 \mathrm{~Hz}$ continuam dentro dos $25 \mathrm{dBA}$, ou o ultrapassam muito ligeiramente, apesar de toda a exuberância da manifestação clínica e auditiva.

Conraux (1990) ${ }^{37}$ relata que o mais comum é o tinnitus nas fases mais tardias. Neste grupo mais idoso, verifica-se afastamento dos limiares já a partir da freqüência $250 \mathrm{~Hz}$ da curva controle.

A freqüência de $4000 \mathrm{~Hz}$ é a mais comprometida em todos os grupos etários, exceto nos mais idosos e com maior tempo de exposição, nos quais a lesão em $4000 \mathrm{~Hz}$ está muito próxima de $6000 \mathrm{~Hz}$.

Taylor et al. (1964) ${ }^{19}$ ao estudarem as perdas 
auditivas em função das freqüências, observam que de $3000 \mathrm{~Hz}$ a $6000 \mathrm{~Hz}$ afetam-se com maior gravidade em $4000 \mathrm{~Hz}$. Na segunda década, verificam que $3000 \mathrm{~Hz}$ se aproxima mais de $4000 \mathrm{~Hz}$, e apenas após a terceira década as freqüências de $2000 \mathrm{~Hz}$ encontram-se muito comprometidas com limiares que ultrapassam $40 \mathrm{~dB}$. Destacam que nos primeiros dois anos de exposição o desvio de limiar não ul trapassa 5 dB. Observam que em 4000 $\mathrm{Hz}$, após um período de el evação do limiar acel erado, diminuem-se os aumentos de limiares desta freqüência com "estabilização" que dura entre 10 e 15 anos. Neste período de estabilização são atingidas as freqüências de $3000 \mathrm{~Hz}, 2000 \mathrm{~Hz}, 1000 \mathrm{~Hz}$. A pós esta fase, há deteri oração embora, mais lenta nas freqüências de $3000 \mathrm{~Hz}, 2000 \mathrm{~Hz}$ e $1000 \mathrm{~Hz}$.

\section{Os limiares médios aproximados do grupo 2-} 4 são:

$\begin{array}{rlrl}250 \mathrm{~Hz} & \rightarrow 20 \mathrm{dBA} & 500 \mathrm{~Hz} & \rightarrow 15 \mathrm{dBA} \\ 1000 \mathrm{~Hz} & \rightarrow 20 \mathrm{dBA} & 2000 \mathrm{~Hz} \rightarrow 30 \mathrm{dBA} \\ 3000 \mathrm{~Hz} & \rightarrow 40 \mathrm{dBA} & 4000 \mathrm{~Hz} & \rightarrow 50 \mathrm{dBA} \\ 6000 \mathrm{~Hz} & \rightarrow 50 \mathrm{dBA} & 8000 \mathrm{~Hz} \rightarrow 40 \mathrm{dBA}\end{array}$

Os limiares médios aproximados do grupo 34 são:

$\begin{array}{rlrl}250 \mathrm{~Hz} & \rightarrow 20 \mathrm{dBA} & 500 \mathrm{~Hz} & \rightarrow 20 \mathrm{dBA} \\ 1000 \mathrm{~Hz} & \rightarrow 25 \mathrm{dBA} & 2000 \mathrm{~Hz} \rightarrow 40 \mathrm{dBA} \\ 3000 \mathrm{~Hz} & \rightarrow 50 \mathrm{dBA} & 4000 \mathrm{~Hz} \rightarrow 55 \mathrm{dBA} \\ 6000 \mathrm{~Hz} \rightarrow 60 \mathrm{dBA} & 8000 \mathrm{~Hz} \rightarrow 50 \mathrm{dBA}\end{array}$

\section{CONCLUSÕES}

1. Trabalhadores com perda auditiva provocada por ruído apresentam li miares audi ométri cos altamente desfavoráveis quando comparados a uma população não-exposta, mesmo em relação ao grupo de pior audição desta população controle.

2. As queixas clínicas auditivas mais freqüentes numa população de trabalhadores com disacusia sensórioneural ocupacional por ruído são de hipoacusia e tinnitus.

3. As freqüências audiométricas mais afetadas dependem da faixa etária e do tempo de exposição ao ruído, sendo que a evol ução do comprometi mento de acordo com o tempo de exposição, seria da seguinte forma:

- Primeira Década de Exposição

1 ㅇ - $4000 \mathrm{~Hz}$

2ㅇ- $6000 \mathrm{~Hz}$

3ㅇ - $8000 \mathrm{~Hz}=3000 \mathrm{~Hz}$

- Segunda Década de Exposição

10 - $4000 \mathrm{~Hz}=6000 \mathrm{~Hz}$

2 ㅇ - $3000 \mathrm{~Hz}$

3ㅇ- $8000 \mathrm{~Hz}$

- Terceira Década de Exposição

1 ㅇ - $4000 \mathrm{~Hz}=6000 \mathrm{~Hz}$

2 - $-3000 \mathrm{~Hz}=8000 \mathrm{~Hz}$

\section{PROPOSTAS}

A fim de que se exerça controle e prevenção da disacusia neuro-sensorial ocupacional por ruído, sugerimos:

1. Todo trabal hador exposto ao ambiente de trabaIho ruidoso deverá realizar testes auditivos completos, incluindo via aérea e óssea e índice de discriminação vocal com periodicidade mínima anual. Estes testes mostraram-se adequados para avaliar a instalação da lesão e suas seqüelas.

2. Alterações nas freqüências de $3000 \mathrm{~Hz}, 4000$ $\mathrm{Hz}, 6000 \mathrm{~Hz}$ e $8000 \mathrm{~Hz}$ deverão ser consideradas como indicativos de evolução da lesão, conforme os parâmetros da conclusão três e de acordo com o tempo de exposição ao ruído.

3. Devido a alta sensibilidade da freqüência de $4000 \mathrm{~Hz}$, recomendamos que os desvios de limiares desta freqüência, mesmo que isolados, detectados nos exames periódicos sejam valorizados com o objetivo de prevenção da disseminação da lesão coclear, principal mente nos grupos mais jovens de até 50 anos de idade.

4. Proposta de parâmetro para avaliação de perdas auditivas por ruído conforme a idade e tempo de exposição.

Estes gráficos (8 a 14) foram realizados tomando-se em conta os limiares médios aproximados da amostragem analisada.

\section{SUMMARY}

\section{Natural history of noise induced hearing loss}

Purpose. To evaluate the clinical and audiometric characteristics of occupational hearing loss induced by noise, according to age and time of exposition in years.

Methods. 222 patients with occupational sensoriumneural hearing loss induced by noise were studied retrospectively, correlating the auditive clinical claims, alterations of audiometric thresholds at fre quencies of $250 \mathrm{~Hz}$ to $8000 \mathrm{~Hz}$, speech discrimination indicator with age and time of exposure. As a control group were used the audiometric threshold of a population of same medium age, without morbid antecedents of hearing illness, as preconized by ISO 1999 (1990). The group were divided into subgroups and three decades of exposure were analyzed.

RESULTS. It was verified that the clinical claims of hipoacusy increases according to the age and time of exposure. The frequency of tinnitus is constant. The audiometric thresholds in the second decade of exposure present variations that depend on theage. The several audiometric curves are paralle, but they are not horizontal. The worst thresholds were found in the high frequencies from $3000 \mathrm{~Hz}$ to $8000 \mathrm{~Hz}$, as a clinical and physiopathological consequences of the commitment of basal areas of cochlea. The speech 
discrimination showed to be worst according to the increase of age and time of exposure.

Conclusion. Patients with hearing loss disacusy induced by occupational noise present characteristic audiometric thresholds that varie according to age and time of exposure to noise. These characteristics defined and resumed in audiometric curves can constitute a standard of comparation, evaluation and control for exposed populations. [Rev Ass Med Bra 2000; 46(2): 143-58]

KEY WORDS: Noise induced hearing loss. Hipoacusy. Epidemiology.

\section{REFERÊNCIA BIBLIOGRÁFICA}

1. World Health Organization. Noise. Environmental. health Criteria 12. Geneva, 1980.

2. ISO 1973a - Acoustics-guide to the measurements of airbone acoustical noi seand evaluation of its effects on man. Genèva. 1973.

3. Hetu, R.; Quoc, H.T.; Duguay, P. - Thelikelihood of detecting a significant hearing threshold shift among noise-exposed workers subject to annual audiometric testing. Ann. Occup. Hyg. 34:361-370, 1990.

4. Habermann, J . - Ueber die schwerhörigekeit der kesselschmiede. Archiv für Ohrenheilkunde, 30:1-25, 1890.

5. Wittmack, D. - Über schädigung des gehörs durch Schalleinwirkung. Z.Ohrenkeilkunde 54:37-80, 1907.

6. Fowller, E.P. - Marked deafened areas in normal ears. Archives of Otolaryngol ogy, 151-155, 1928.

7. Temkin, J. - Die Schädigung des ohres durch Lärm und Erschütterung. Monatschrift für Ohrenheilkundeund Laringo-rhinol ogie 67:257, 1933.

8. Bunch, C.C. The diagnosis of occupational or traumatic deafness. A historical and audiometric study. The Laryngoscope 47:615-691, 1937.

9. Larsen, B. - Investigations on noise in certain factories. Acta Otolaryngol. (Stockh), 34:71-77, 1946.

10. Almeida, H. - Influence of electric punch card machines on the human ear. Archives of Otolaryngol ogy 51:215-222, 1950.

11. Mocellin, L. - Profilaxia dos traumatismos sonoros na surdez profissional. Curitiba, 1951. Tese de Livre Docência - F aculdade de Medicina da Universidade do Paraná.

12. AMA-Council on Physical Medicine. Tentativestandard procedure for evaluating the percentage loss of hearing medicolegal cases. Council on Physical Medicine, J . Am. Med. Assoc., 133:396, 1947.

13. AMA - Council Physical Medicineand Rehabilitation. Principles for evaluating hearing loss. J . Am. Med. Assoc., 157:1408, 1955.

14. Gravendeel, D.W. \& PLOMP, R. - The relation between permanent and temporary noise dips. Archives of Otolaryngol ogy, 69:714-719, 1959.

15. Harris, J .D.; Haines, H.L.; Myers, C.K. - The importance of hearing at $3 \mathrm{kc}$ understanding speed speech. Laryngoscope 1960; 70:131-146.

16. AMA-Commiteeon Medical Rating of Physical I mpairment: Guide to the evaluation of permanent impairment: ear, nose and throat and related structures. J . Am. Med. Assoc., 177:489-501, 1961.

17. Waal, J.V.; Holland, L. - Peculiarities of noise- induced hearing loss. Ann. Otol. 70:208-223, 1961.

18. Glorig, A.; Ward, W.D.; Nixon, J - - Damage risk criteria and noiseinduced hearing loss. Archives of Otol aryngol ogy 74:413-423, 1961.

19. Taylor, W. et al. - Study of noise and hearing in jute weaving. J . Acoust. Soc. Am., 38:113-120, 1964.

20. Atherley, G.R.; Noble, W.G.; Sugden, D.B. - Foundry Noiseand hearing in Foundrymen. Ann. Occup. Hyg., 10:255-261, 1967.
21. Marone, S. - Estudo Médico-Legal das Perdas da Audição. Edição Saraiva, São Paulo, 1968. 85 p.

22. Ward, D.W. - The identification and treatment of noiseinduced hearing loss. Otolaryngologic Clinic of North Americal, 2:89-110, 1969.

23. Miller, J.D. - Effects of noise on the quality of human life. Central Institute for the Deaf, St. Louis (Special Contract Report Prepared for the Environmental Agency, Washington, D.C.) Occupational Exposure to Noise, NIOSH, 1972, USA.

24. Clark, W.W. \& Bohne, A.B. - Animal model for the 4-K Hztonal Dip. Ann.Otol., 87 (Suppl. 51), 1978.

25. Pereira, C.A. - Surdez profissional em trabalhadores metalúrgicos: estudo epi demi ol ógi co em uma Indústria da Grande São Paulo. São Paulo, 1978. Dissertação de Mestrado F aculdade de Saúde Pública da U niversidade de São Paulo.

26. Portaria 3214DE 08/06/78- Ministério doTrabal ho do Brasil.

27. AMA-Council of ScientificAffairs: Guidefor the evaluation of Hearing Handicap. J. Am. Med. Assoc., 241:2055-2059, 1979.

28. Atherley, G. \& J ohnston N. Audiometry. The ultimate test of sucess? Ann. Occup. Hyg., 27:427-447, 1983.

29. Alberti, P.W. Thedinical assesment of industrial hearinglossa case report and discussion. TheJ ournal of Otolaryngol ogy 11:94-9, 1982.

30. Almeida, S.I . Estudo clínicoefisiopatol ógico da lesãoauditiva induzida pelo ruído. Revista Brasileira de Saúde Ocupacional., 13:28-33, no 52, 1985.

31. Caval canti, C.V.; Rezende de Almeida, E.; Butugan, O. Estudo audiométricoemambienteruidoso. Oto-rhino 1:15-28, nำ4, 1986.

32. Axelsson, A. \& Hamernik, R.P. - Acute acoustic trauma. Acta Otol aryngol. (Stockh) 104:225-233, 1987.

33. Osguthorpe, J.D., ed. - Guide for conservation of hearing in noise. American Academy of Otolaryngology - Head and Neck Surgery Foundation. Subcomittee on the Medical Aspects of Noise of the Comitee on Hearing and Equilibrium. 1988.

34. Osguthorpe, J.D. \& Klein, A.J - - Hearing Compensation E valuation. American Academy of Otolaryngology-Head and Neck Surgery Foundation, 1989.

35. Clark, W.W. \& Popelka, G.R. - Hearing levels of rail road train men. Laryngoscope 99:1151-1157, 1989.

36. ISO 1999 - Acoustics-Determination of occupational noise exposure and estimation of noise-induced hearing impairment. Second Edition. Genève. 1990.

37. Conraux, C. Surdités professionnelles. La Revuedu Praticíen, 40(19):1762-5, 1990.

38. Talbott, E.O. et al. Noise induced hearing loss: a possible marker for high blood pressure in older noise-exposed popuIation. J ournal of Occupational Medicine, 32:690-697, 1990.

39. Phaneuf, R. \& Hetu, R. - An epidemiol ogical perspective of the causes of hearing loss among industrial workers. TheJ ournal of Otolaryngol ogy., 19:1, 1990. p.31-40.

40. Vincent, M.; Estève-Fraysse, M.J .; Fraysse, B. - Diagnostic des surdités de perception chez l'adulte. La Revue du Praticien 40(19):1751-1761, 1990. vol.40. oㅜ19.

41. Úlehlová, L.; Branis, M.; J anisch, R. - Acoustictrauma in mine workers revealed by temporal bone necropsy. Acta Otolaryngol. (Stockh) (Suppl. 470):97-108, 1990.

42. Hanner, P. \& Axelsson, A. Acute acustic trauma. An emergency condition. Scand. Audiology., 17:57-63, 1988.

43. Riko, K. et al. - Hearing aid usage in occupational hearing loss claimants. The ournal of Otolaryngology 19:25-30 ํㅜ1, 1990.

44. Lim, D.P. \& Stephens, S.D.G. - Clinical investigatioin of hearing loss in theelderly. Clin.Otol aryngol . 16:288-293, 1991.

45. Almeida, S.I. Diagnóstico diferencial da Disacusia Neurosensorial induzida pelo ruído. Rev. Associação Médica Brasileira 37:150-152, 1991.

46. MottaSinger,J .\& Andrade, D.F. - Análisededados Iongitudinais. VII SINAPE. Simpósio Nacional de Probabilidadee Estatística. 1986. UNICAMP (Universidade Estadual de Campinas).

47. Pialoux, P.; Cavigneux, A; Rainyille, H.J . - Surdité Professionelle. Encyclop. Med.Chir. Oto-Rhino-Laryngologie., 1:20199A-10, 1974. 